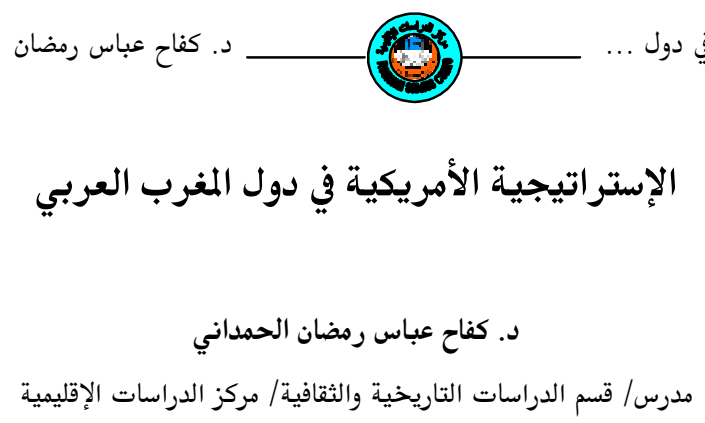

مستخلص البحث

إن الإستراتيجية الأمريكية تجاه دول المغرب العربي لا يمكن فصلها بتاتـا عـن طبيعسة العلاقـات

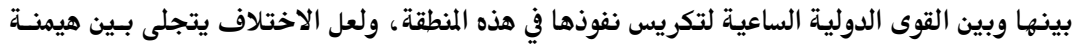

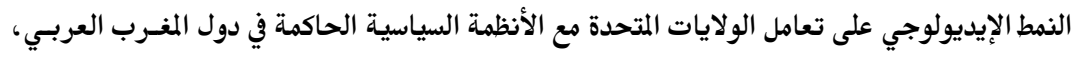

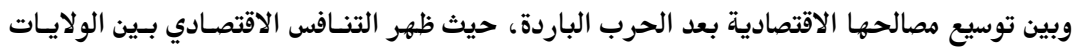

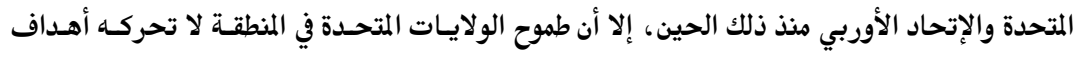

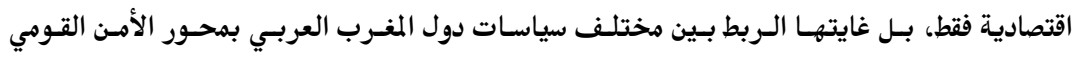

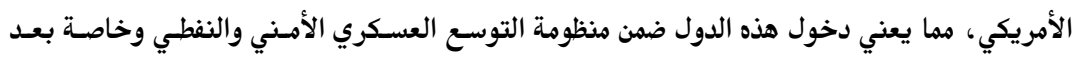

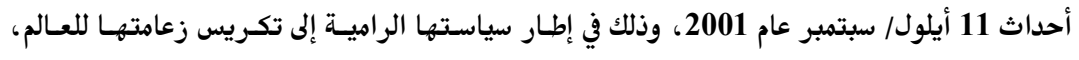

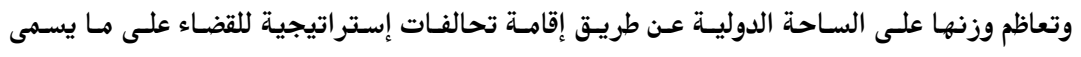

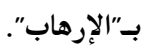

المقدمة

تعتبر منطقة المغرب العببي إحدى الساحات الدولية الأساسية التي يجري عليها اختبار

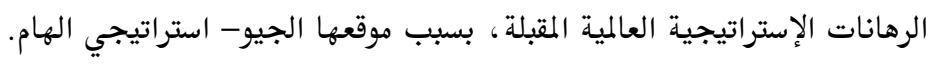

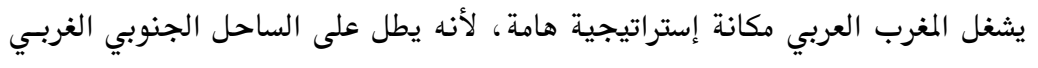

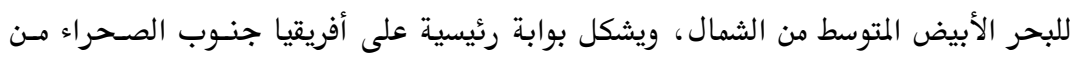

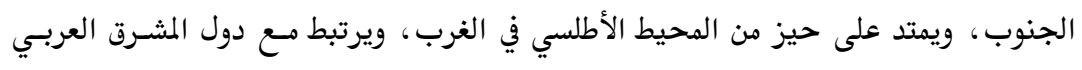

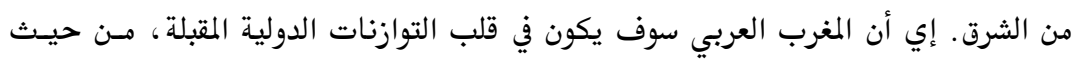

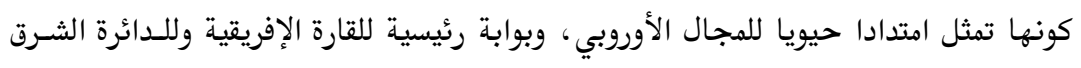

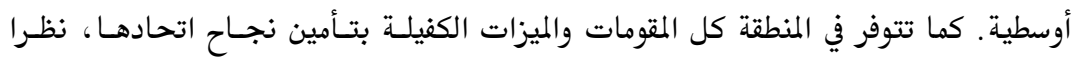




\section{دراسات إقليمية 8 (23)}

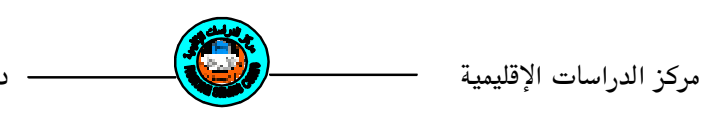

للقواسم المشتركة التي تجمع بين بلدانها على غرار الثقافة والموقع الجغرافي والموارد الطبيعية

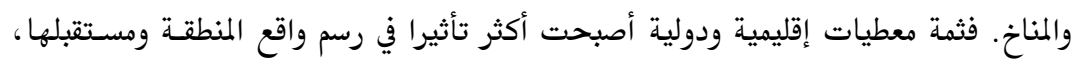

وخاصة في ظل التحول البارز في مسار العلاقات الأوروبية-الأمريكية.

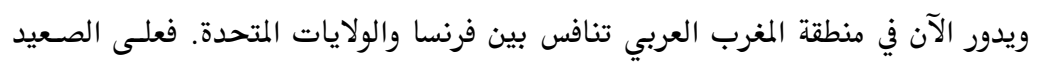

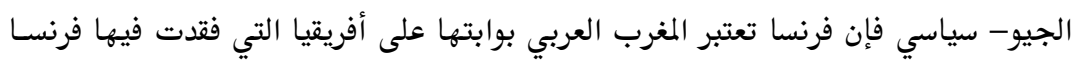

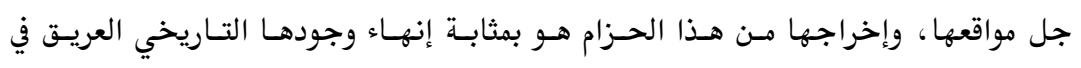

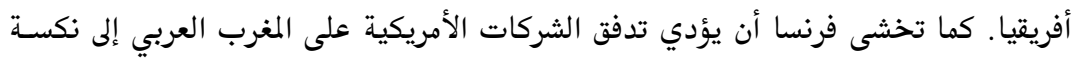

$$
\text { للاقتصاد الفرنسي، الذي يعول كثيرا على الأسواق المغاربية. }
$$

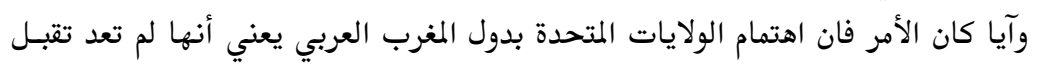

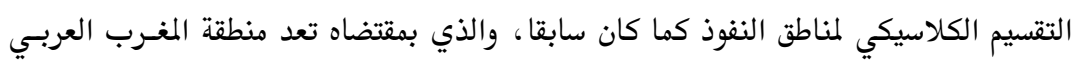

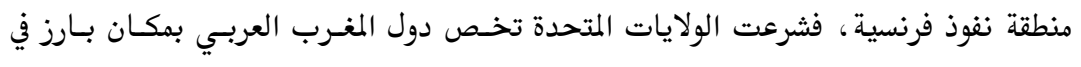

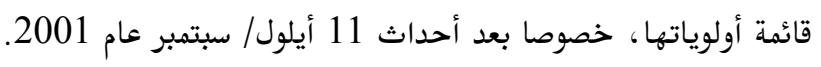

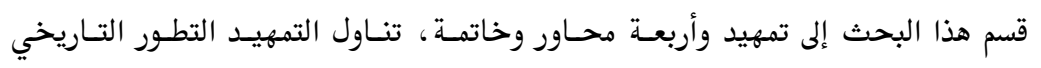

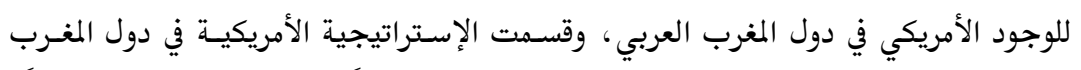

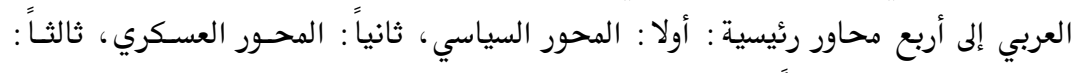

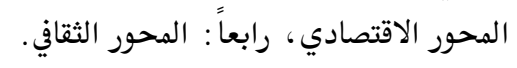

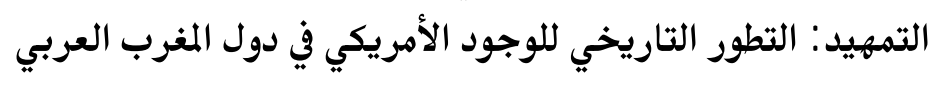

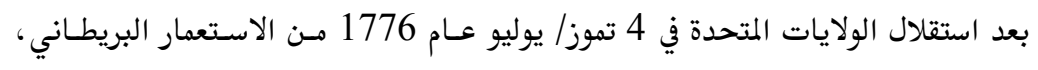

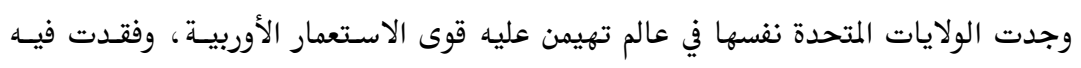

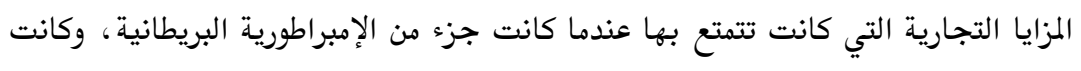

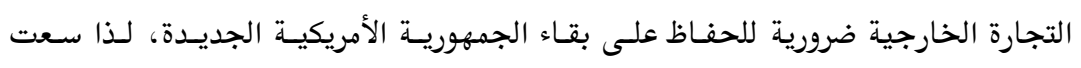

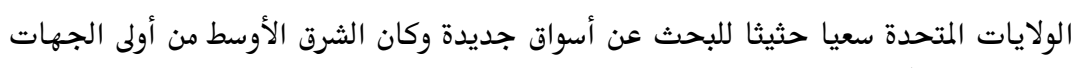
التي قصدتها 'ال.

ظهرت السفن التجارية والحربية الأمريكية في دول الشرق الأوسط وشمال أفريقا في أواخر

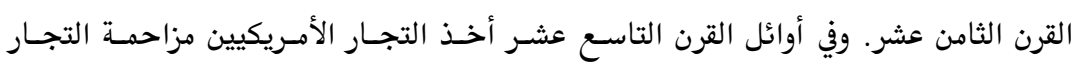


د. كفاح عباس رمضان الإستراتيجية الامريكية في دول ...

الإنكليز ومنافستهم, وكان نجاح هذه العمليات التجارية يتوقف على موقف الحكام المسلمين

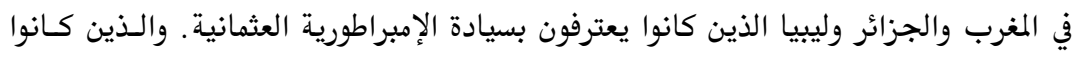

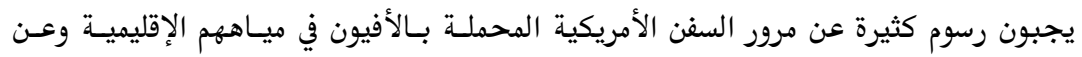
تزويدهم بالماء والمأكولات أثناء زيارة المرافئ العربية وضمان سلامتها (2).

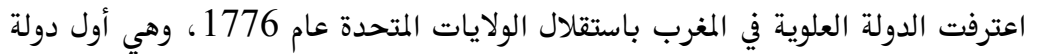

$$
\text { خارجية تعترف باستقلالها 3. }
$$

بدأت الولايات المتحدة علاقاتها الدبلوماسية مع الشرق الأوسط في أيار/ مايو عام 1784

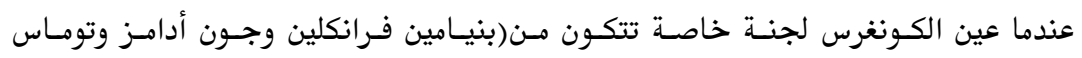
جيفرسون) لإقامة علاقات تجارية والتفاوض مع دول المغرب العربي (4).

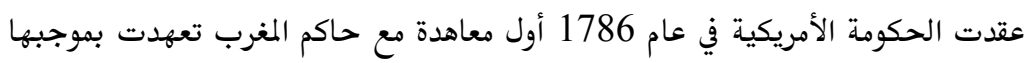

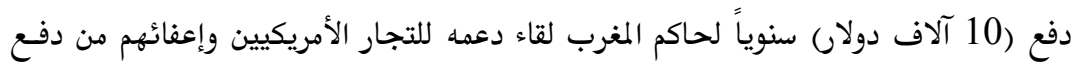
رسوم الترانزيت (5). لكن لم تستطع الولايات المتحدة عقد معاهدة مماثلة مع حكام الجزائر وولاية طرابلس في

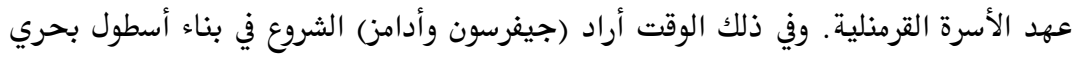

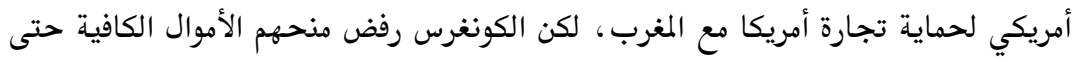

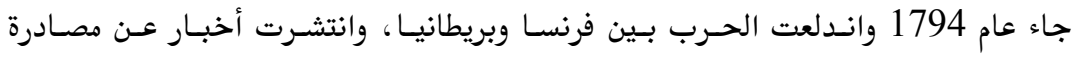

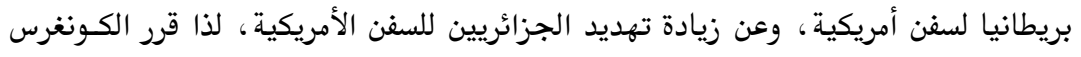

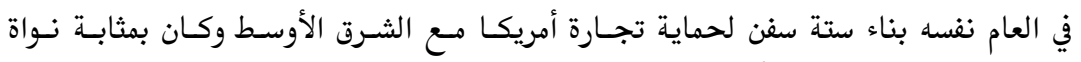
الأسطول الأمريكي الحالي (6). كان البحارة الجزائريون يتعرض لسفن الولايات المتحدة، فاستولوا في تمهوز/ يوليـو عـام

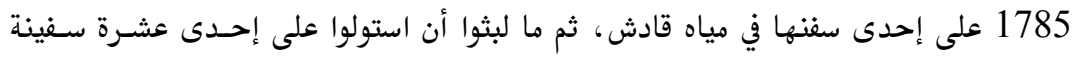

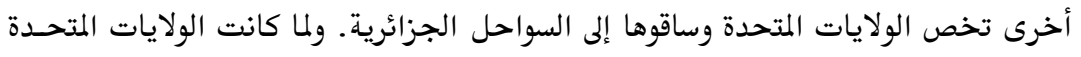

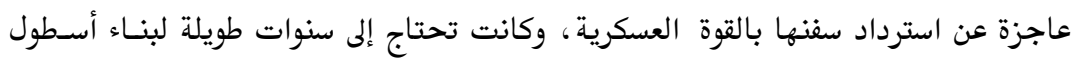

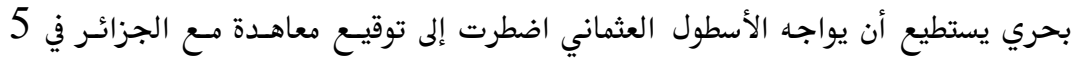

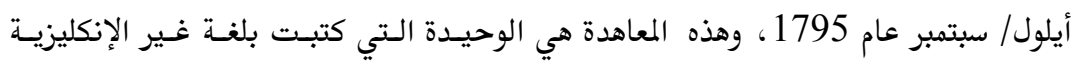




$$
\text { دراسات إقليمية } 8 \text { (23) }
$$

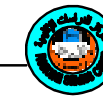

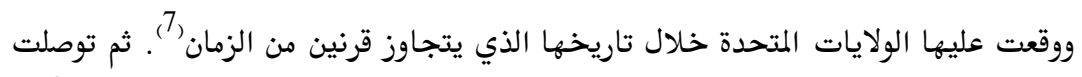

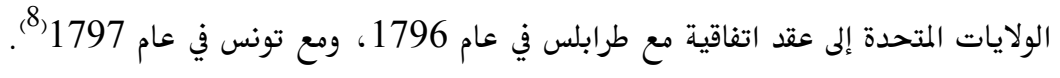

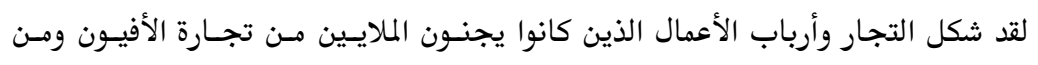

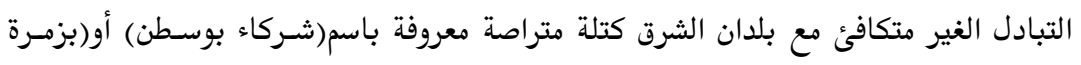

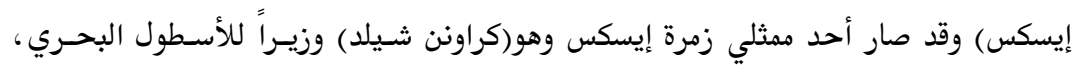

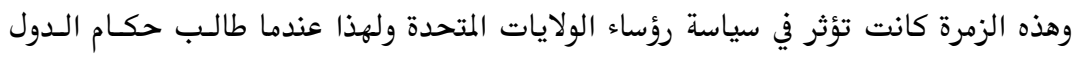

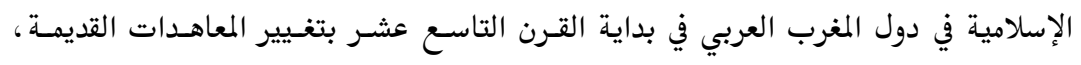

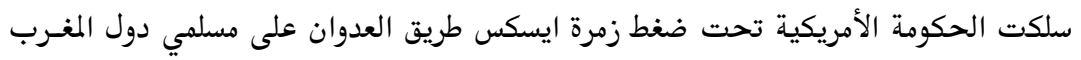
العربي (9). ظهر الأسطول الأمريكي الحربي في البحر البيض المتوسط في عـام 1800 تحست ذريعـة

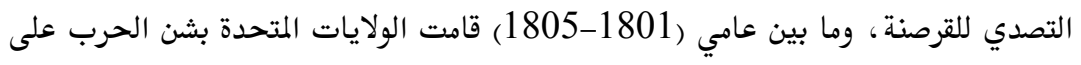

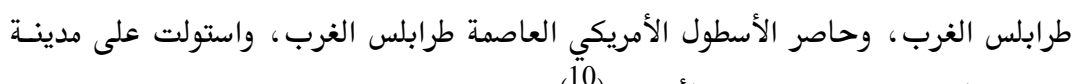
درنة, ورفعت على قلعتها العلم الأمريكي (10).

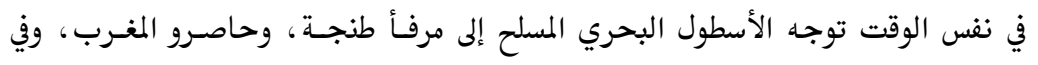

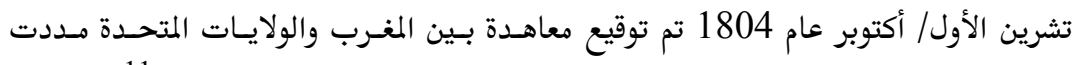

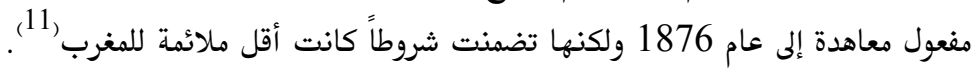

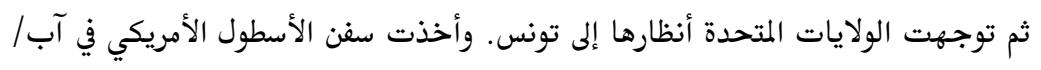

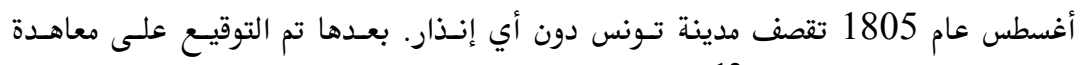
أمريكية تونسية غير متكافئة (12). وفور توقيع معاهدة الصلح الأمريكية البريطانية عام 1815 شرعت أمريكا بتنفيذ خطتها

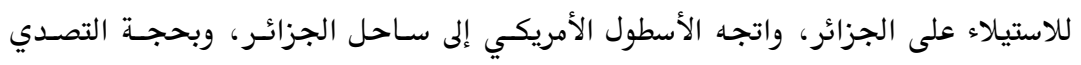

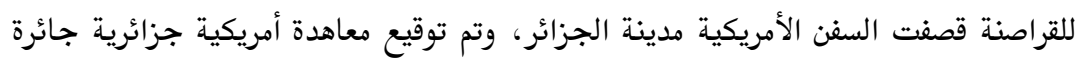
في 23 كانون الأول/ ديسمبر عام 1816. وفي نفس الوقت توجه أسطول حربي أمريكي وقام بهجمات جديدة على مدن تونس وطرابلس الغرب، واستطاع الأمريكيسون أن يجنسوا أمسوالا كبيرة بالقوة رغم معاهدة الصلح الموقعة مع هذين البلدين (13). 
د. كفاح عباس رمضان الإستراتيجية الامريكية في دول ...

أن سياسية الولايات المتحدة تجـاه الشـرق الأوسـط خـلال تلكـ الفـترة المبكـرة، كانست

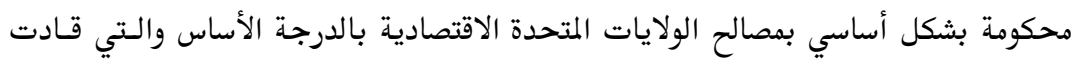

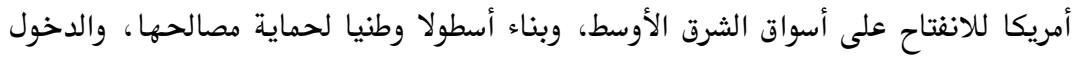

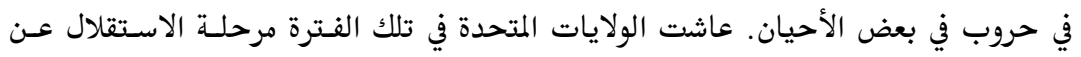

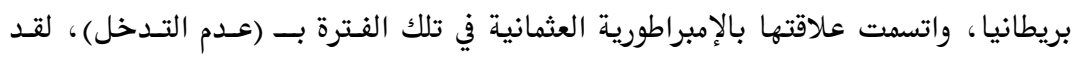

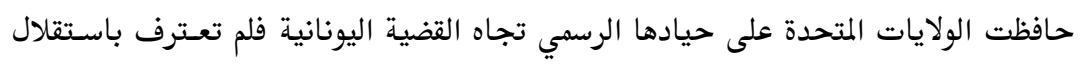

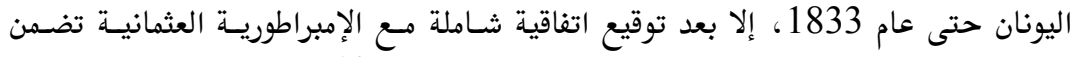

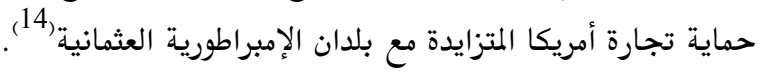

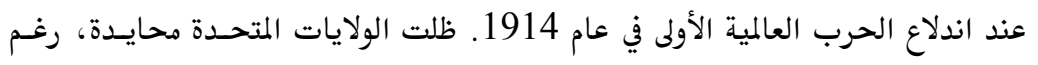

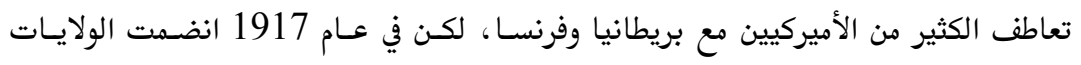

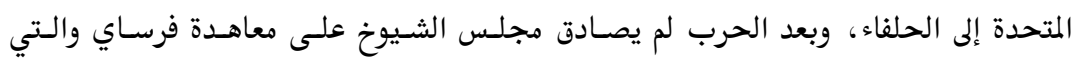

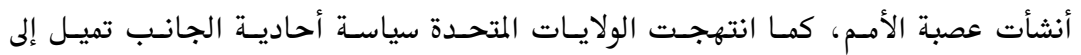
الانعزالية(15). وخلال المراحل الأولى للحرب العالمية الثانية كانت الولايات المتحدة على الحيـاد، لكـن

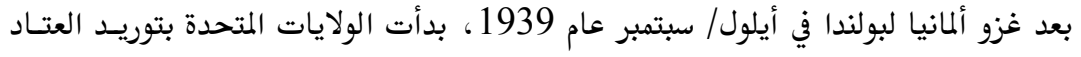

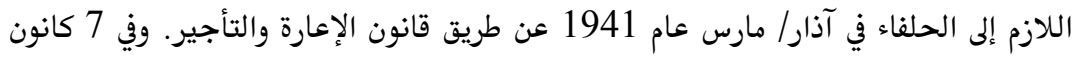

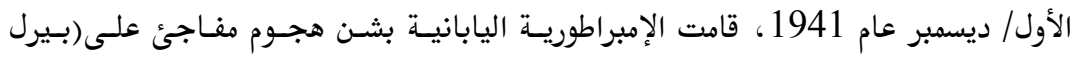

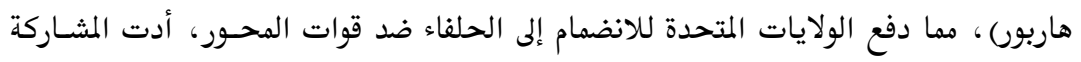

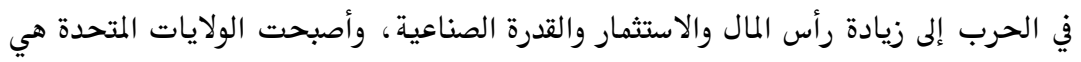

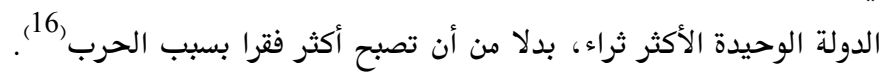

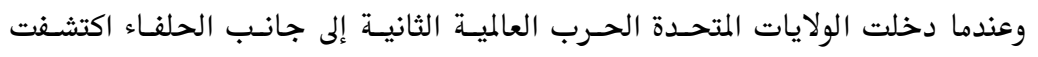

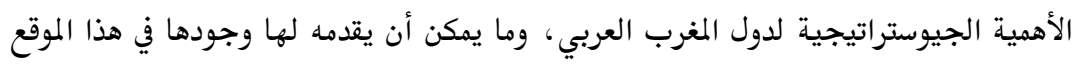

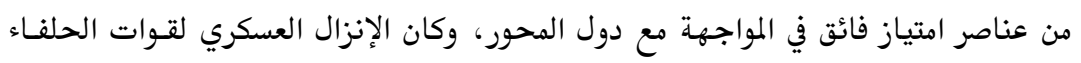

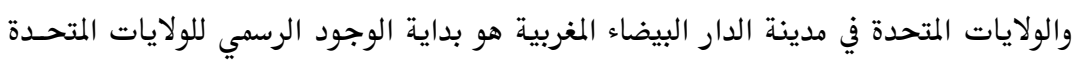




$$
\text { دراسات إقليمية } 8 \text { (23) }
$$

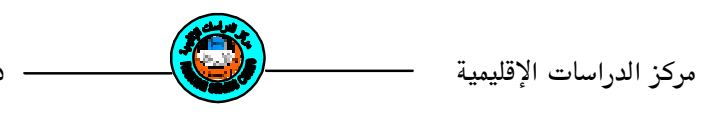

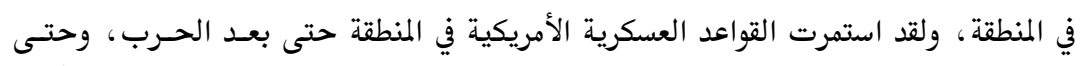

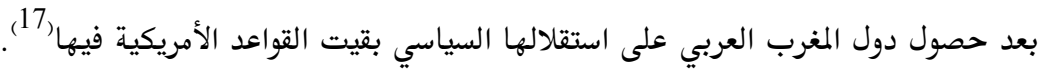

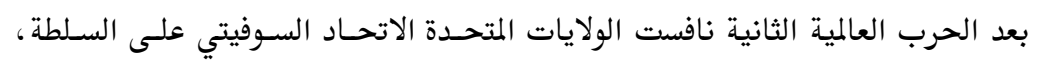

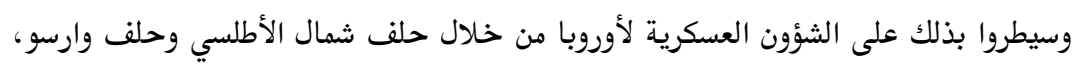

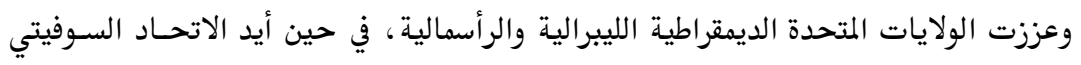

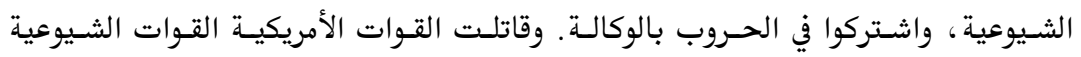
الصينية في الحرب الكورية (1950-1953) (19). في فـترة الحسرب البـاردة لم تكـن الدبلوماسـية الأمريكيـة جـادة في التـدخل في القضـايا

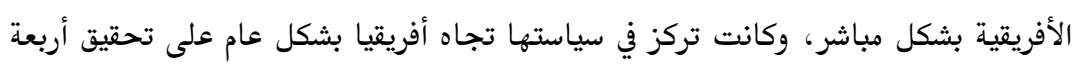

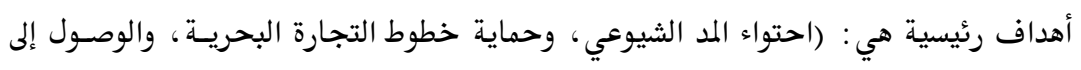

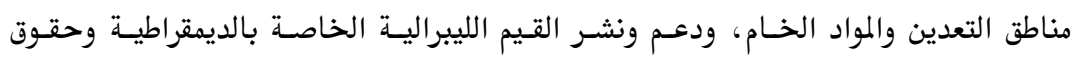

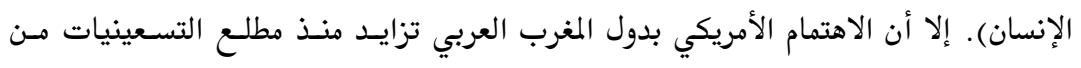

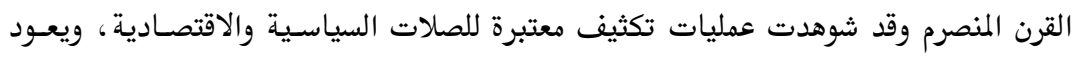

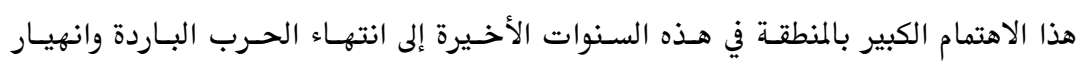

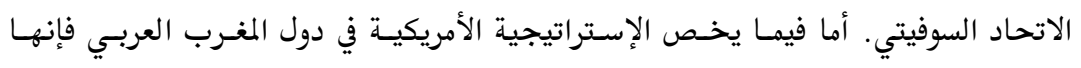

$$
\text { أولا: المثلت في أربعة محاور:- }
$$

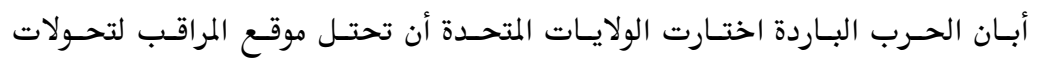

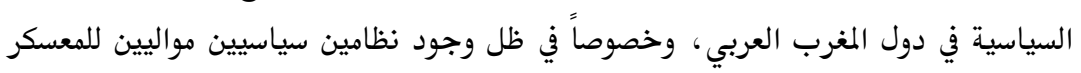

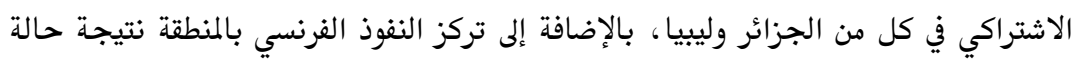

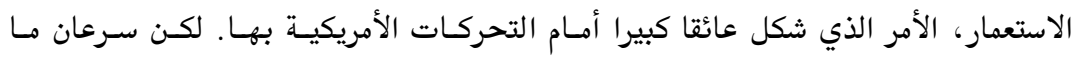

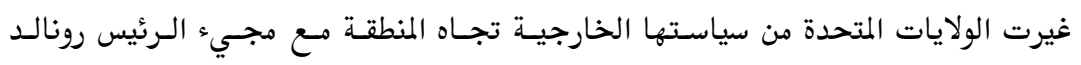

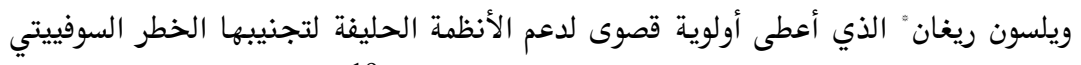

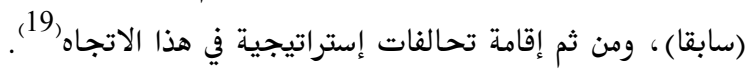




$$
\begin{aligned}
& \text { د. كفاح عباس رمضان } \\
& \text { (3) } \\
& (-2) \\
& \text { الإستراتيجية الامريكية في دول . }
\end{aligned}
$$

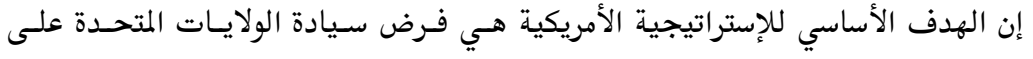

$$
\begin{aligned}
& \text { العالم. وهذا قاد الولايات المتحدة إلى منافسة الاتحاد السوفييتي، الدولة الوحيدة التي تملك لقدئك }
\end{aligned}
$$

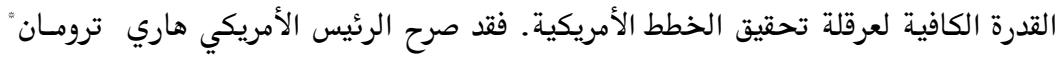

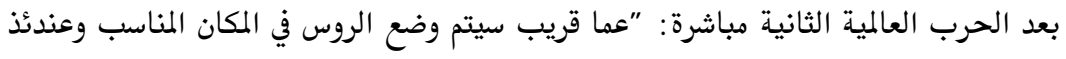

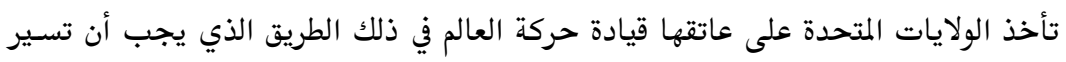

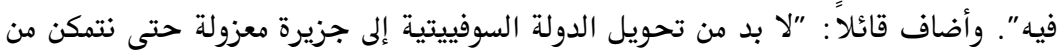

$$
\begin{aligned}
& \text { السيطرة على بقية العالم" (20.2. }
\end{aligned}
$$

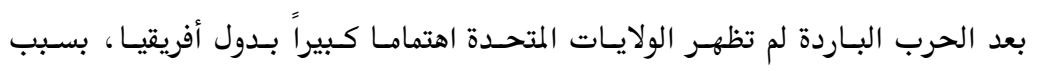

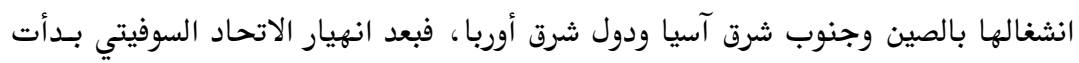

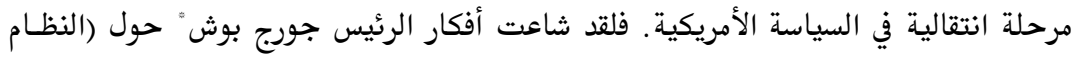

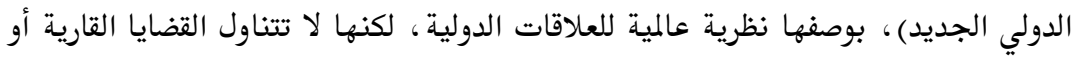

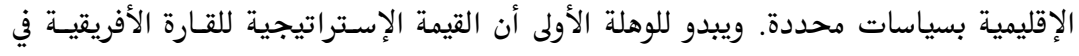

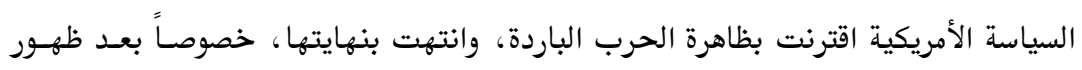

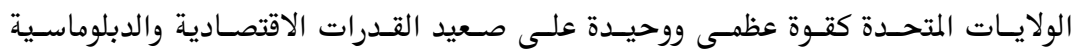

$$
\begin{aligned}
& \text { والعسكرية).21. } \\
& \text { أن هدف الإستراتيجية الأمريكية للمرحلة القادمة هـو المحافظـة على موقـع الولايـات }
\end{aligned}
$$

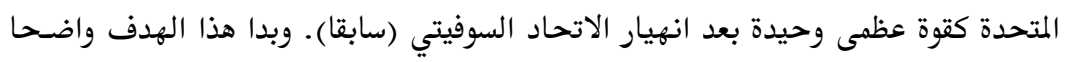

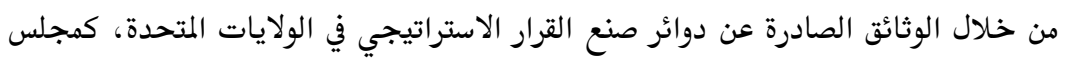

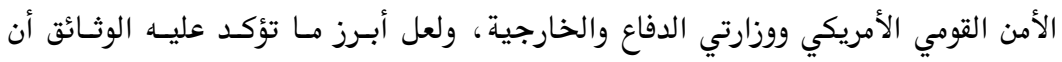

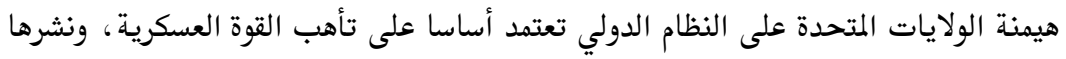

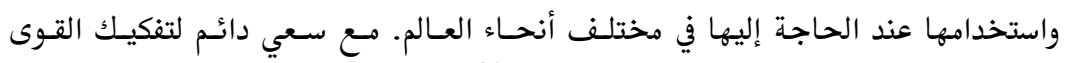

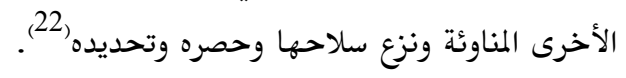

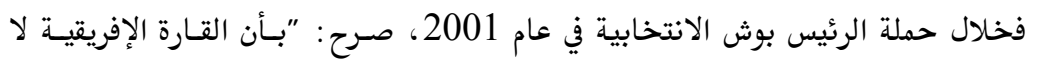

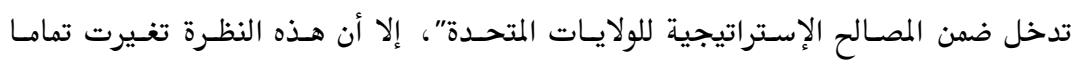

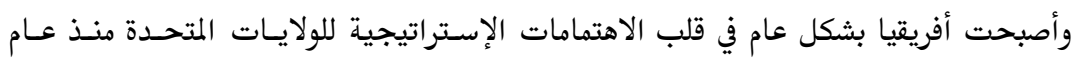


2003. وجاء هذا الاهتمام المتزايد تماشيا مسع الإسـتراتيجية التوسعية التي تبنتهـا إدارة

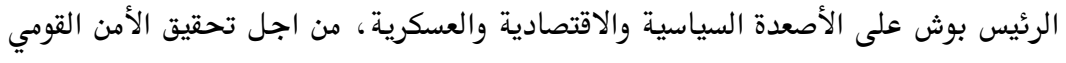

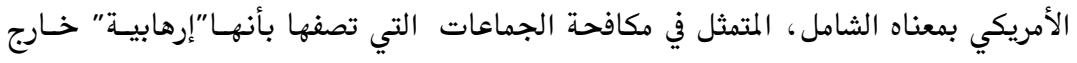

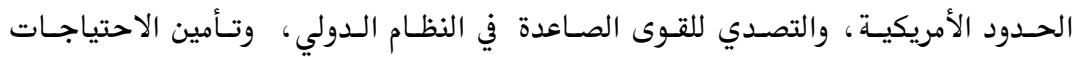

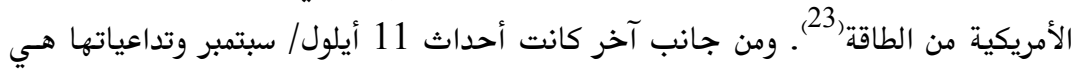
السبب في إحداث تلك النقلة النوعية، فما كان في الهامش أصبح في بؤرة الاهتمام، وأصبح التحيح

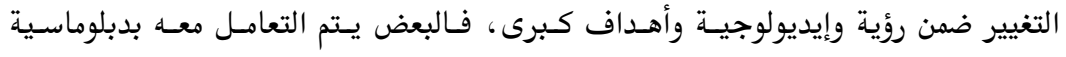

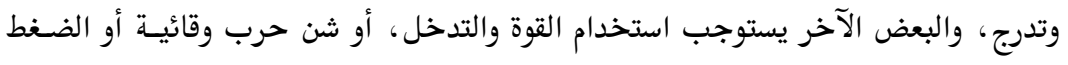

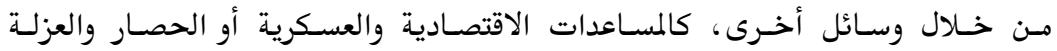
السياسية(24.

وتطبيقا للإستراتيجية الأمريكية الجديدة تم إطلاق هبـادرة الشـراكة هـع الشـرق الأوسط (MEPI)

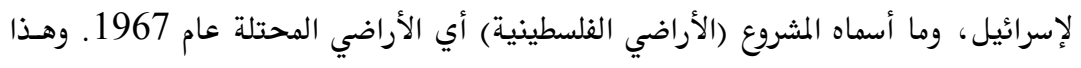

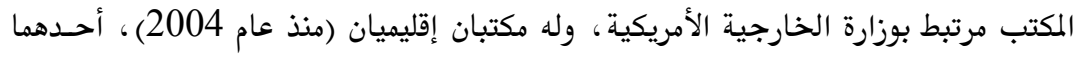
في تونس والثاني في أبو ظبي (الإمارات) ، وله مكاتب فرعية في كل سفارة أمريكية في البلدان

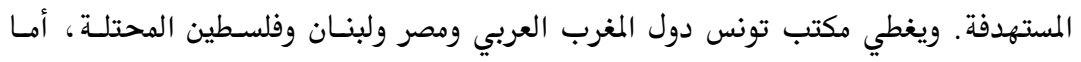

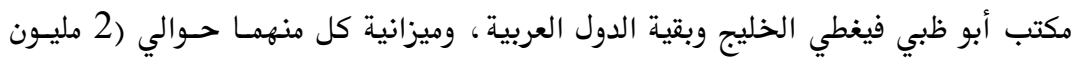

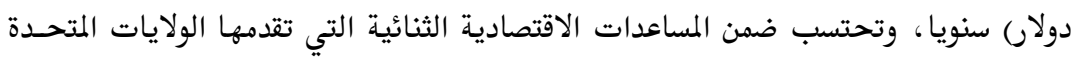

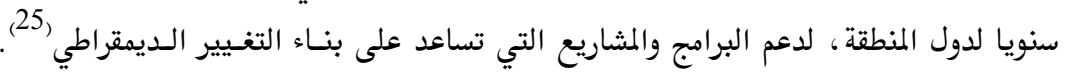

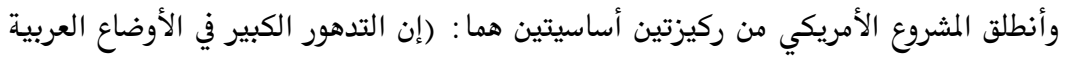

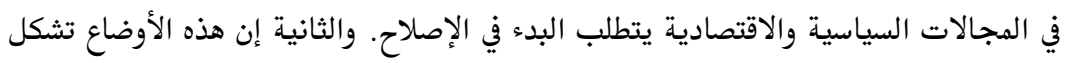

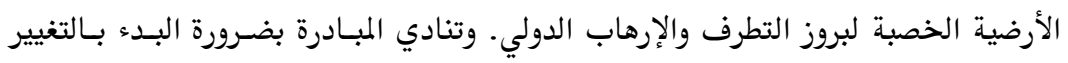

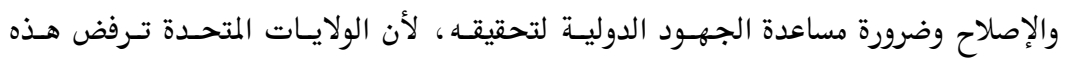

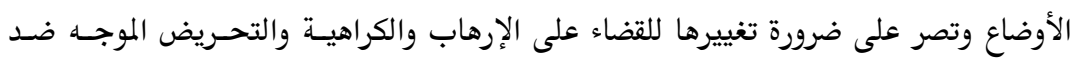
المصـالح الأمريكيـة وضسد إسـرائيل) (26. أهـا الأهـداف المعلنـة فهـي : (دعـم الديمقراطيـة ، 


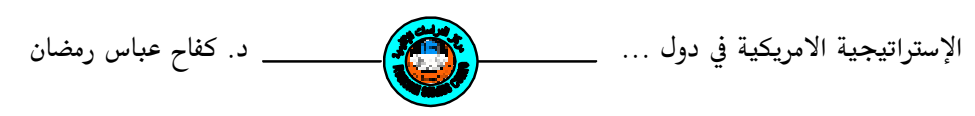

$$
\begin{aligned}
& \text { والإصلاح الاقتصادي وتطبيق التزامات اتفاقيـة التجـارة الحـرة، وإصـلاح التعليم، وتمكين } \\
& \text { المرأة، وتدريبها على القيادة'27. }
\end{aligned}
$$

لقد توصلت الولايات المتحدة إلى القناعـة بضـرورة تغسيير الأوضـاع السياسية في المنطقـة العربية. وتقر الولايـات المتحسدة مسن جهـة ثانيـة بجـدوى النصسيحة الـتي قـدمها الخـبراء

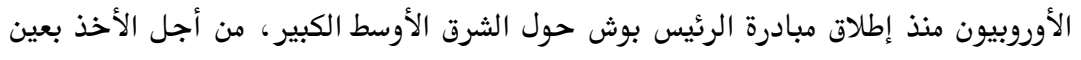

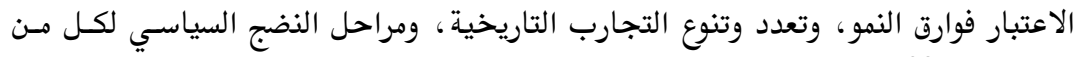
دول المنطقة).28.

اكتفت دول المغرب العربى بمراقبة ردود الفعل الآتية مسن المشـرق على مبـادرة (الشـرق

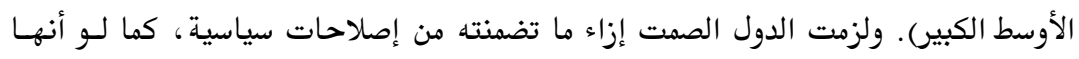

$$
\text { كانت غير معنية بها (29). }
$$

في عام 2006 أي بعد مرور أربعة أعوام على مبادرة الشراكة مع الشرق الأوسط (ميبى)،

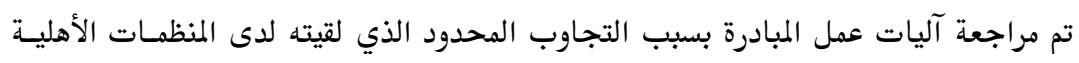

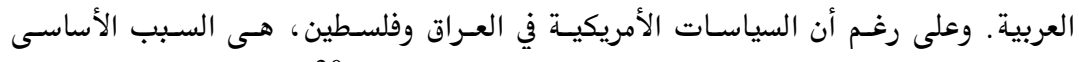

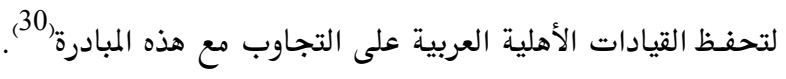

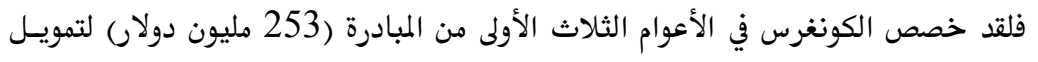

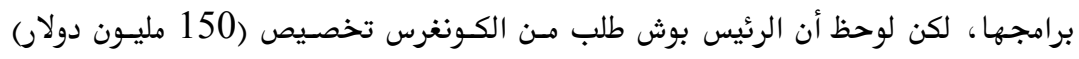

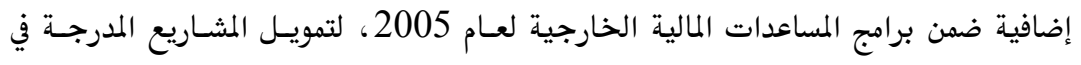

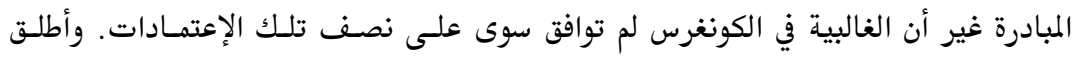

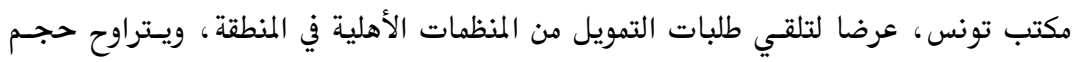

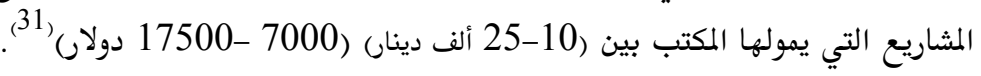

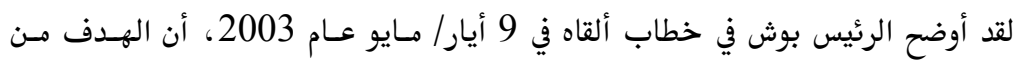

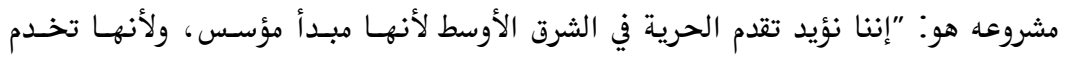

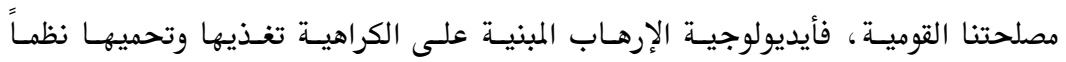
طغيانية" (32. (32. 
بعدها انعقد منتدى المستقبل في المغرب بقيادة الولايات المتحدة في كانون الأول/ ديسمبر

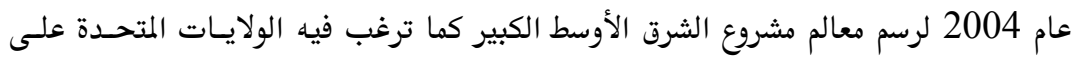

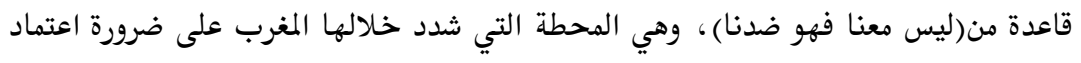

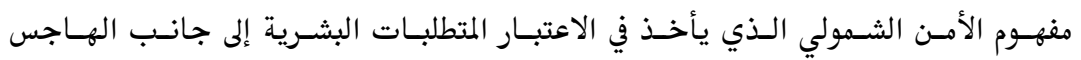
الأمني (33).

وشكلت زيارة رامسفيلد وزيـر الدفاع الأمريكي للمغـرب (12-13 شـباط/ فبرايـر عـام 2006) ، إحدى أبرز المحطات في تاريخ العلاقات المغربية الأمريكية خلال القرن العشرين.

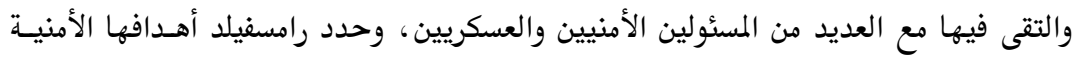

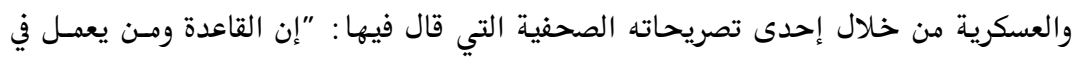

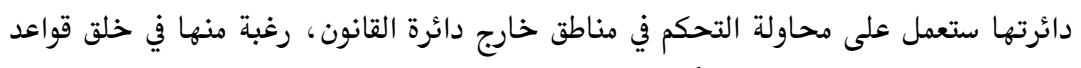

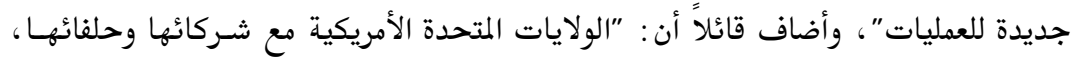

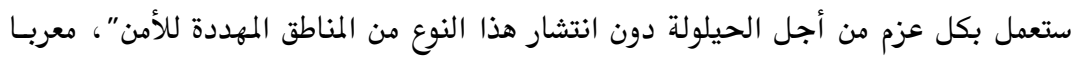

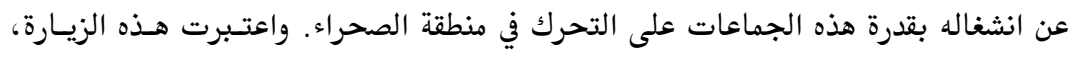

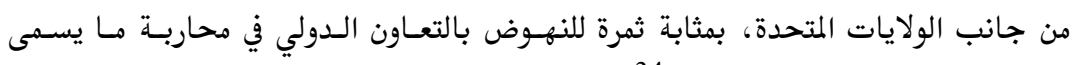
بالإرهاب القادم من منطقة الساحل (34).

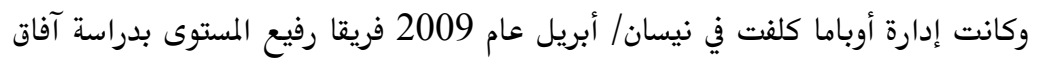

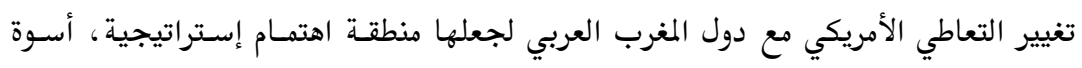

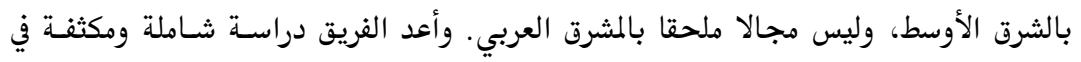

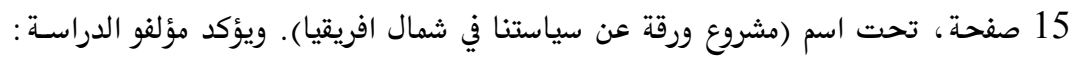

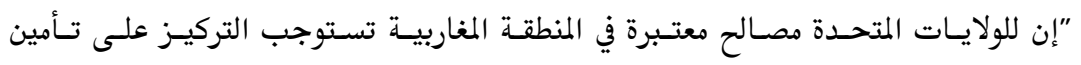

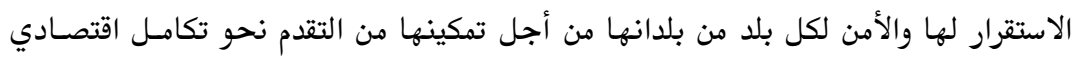

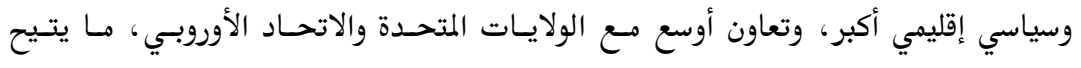

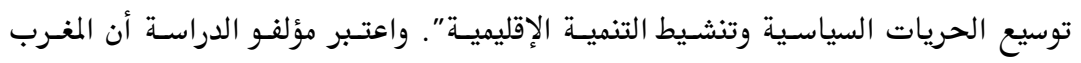

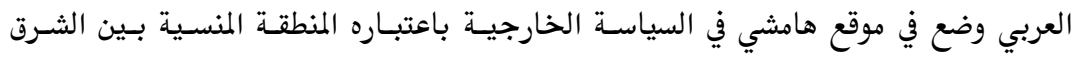

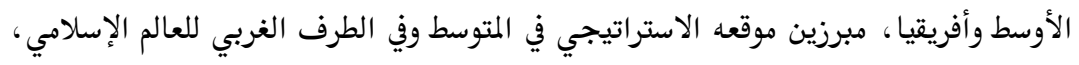


د. كفاح عباس رمضان الإستراتيجية الامريكية في دول ...

ومخاطر تنامي الإرهاب فيه والفرص الاقتصادية والثروات الطبيعية التي يمنحهـا للولايسات

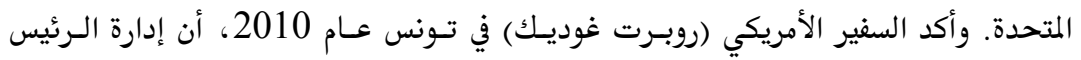

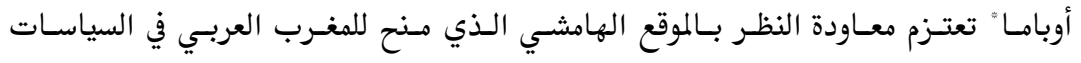

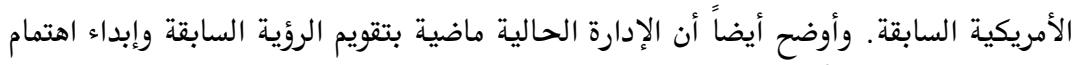
أكبر لشمال إفريقيا (35).

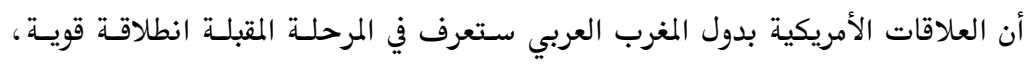

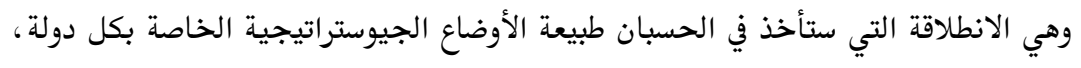

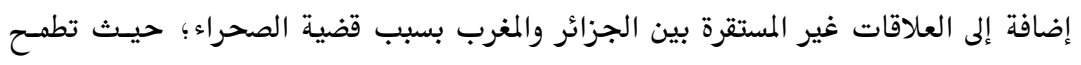

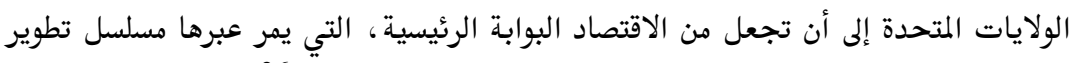
العلاقة السياسية إلى مستوى الشراكة الإستراتيجية مع دول المنطقة (36).

ثانياً: المحور العسكري لقد حددت مراكز صنع القرار الأمريكى نمط وسلوك السياسة الخارجية بلباسها الحربى,

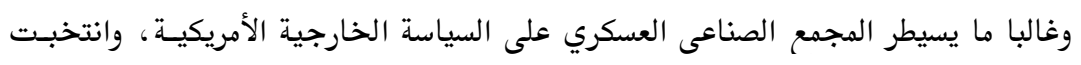

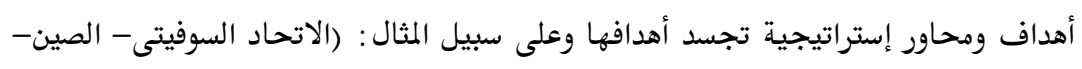

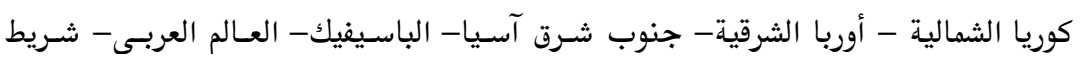

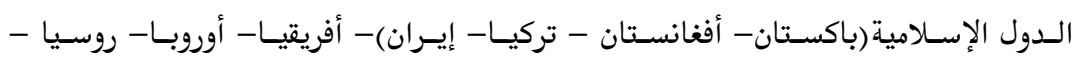

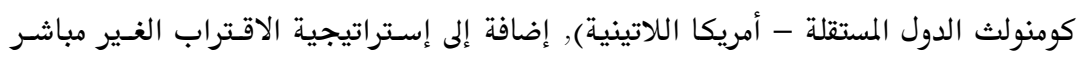

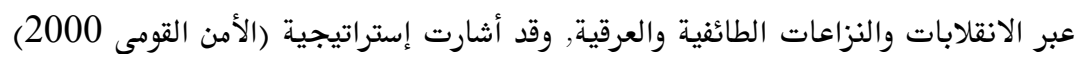

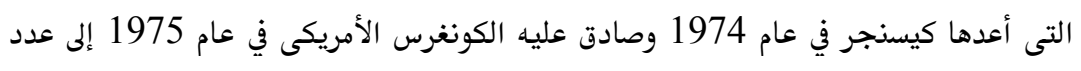

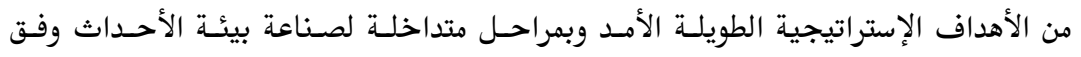
تكتيكات وصراعات سياسية وعسكرية مفبركة (37).

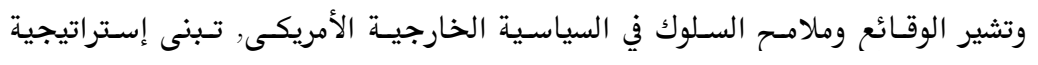

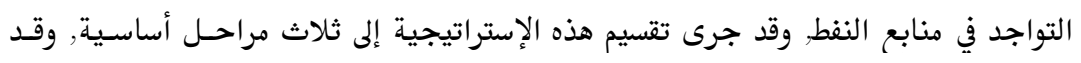

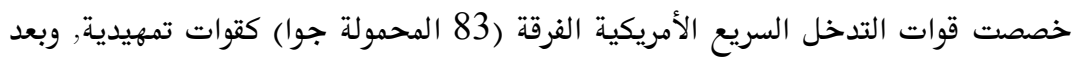


حرب الخليج الأولى (الحرب العراقية-الإيرانية) تمكنت من الوصول إلى مياه الخليج في عـام

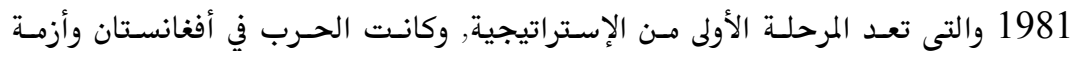

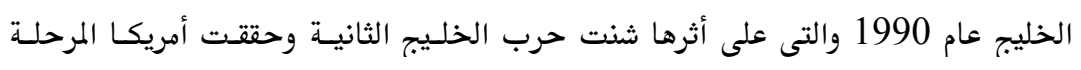

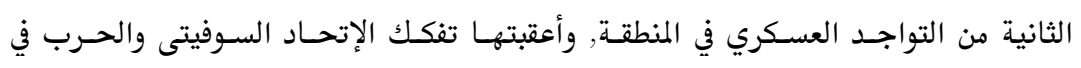

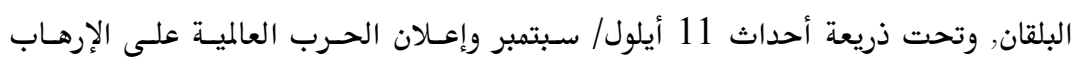

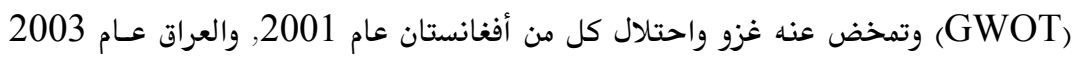
وهى المرحلة الثالثة من إستراتيجية التواجد (38).

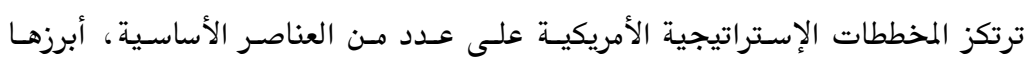

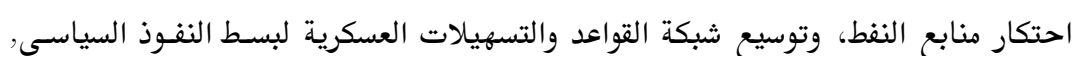

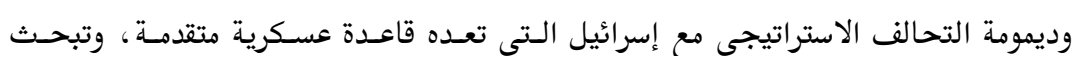

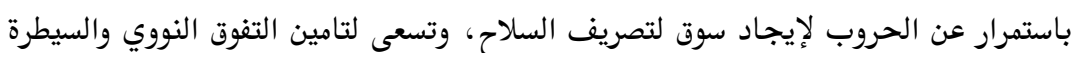

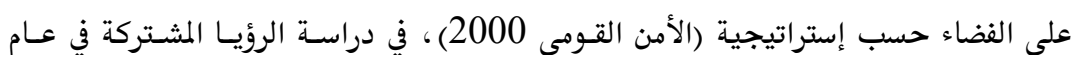

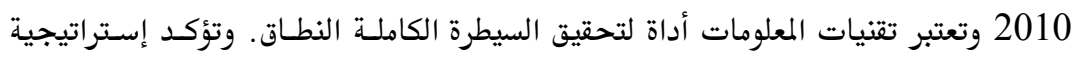

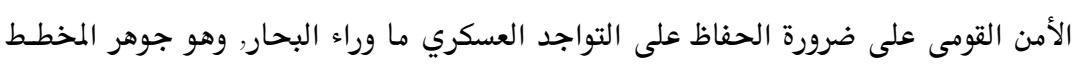

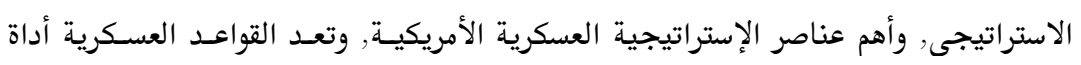

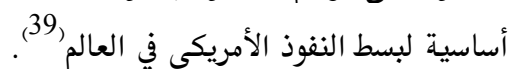
بعد الحرب العالمية الثانية لجأت الولايات المتحدة إلى استخدام أو التهديد باستخدام

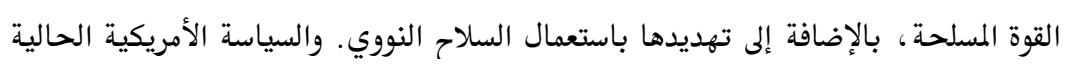

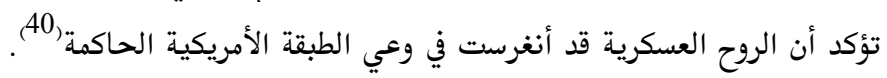

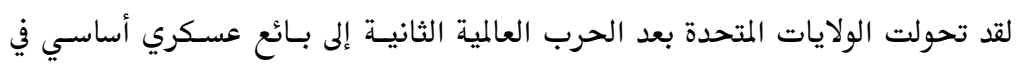

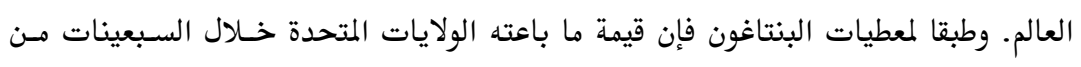

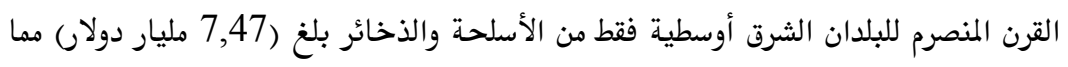
شكل ( 57\%) من مجموع مبيعات الولايات المتحدة من السلع العسكرية إلى العـالم خـلال العـال

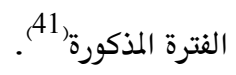


د. كفاح عباس رمضان

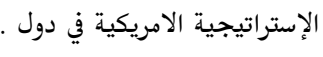

في عهد الرئيس بيل كلينتونْ تم الإعلان عن مبادرة مسؤولية الأزمسة الإفريقيسة، لإقاهـة

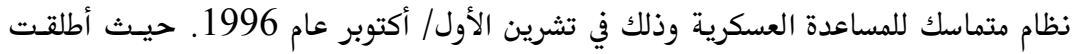

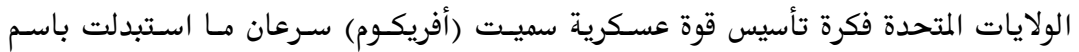

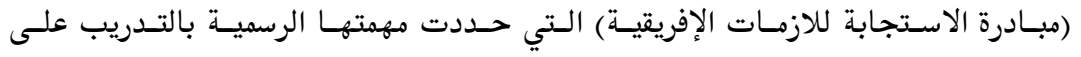

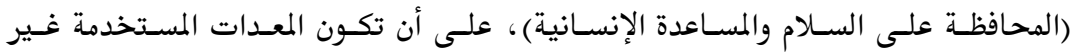
قاتلة. وفي الواقع ترمي هذه المبادرة إلى تحديث عمل القوات المسلحة في البلدان الإفريقيـة

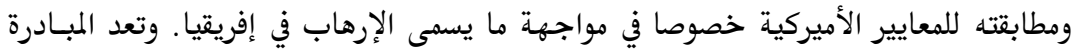

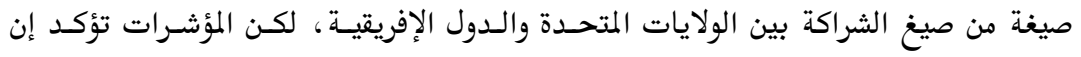
الولايات المتحدة قد خفضت استحقاقات المساعدات الاقتصادية لإفريقيا من (2 مليـار دولار)

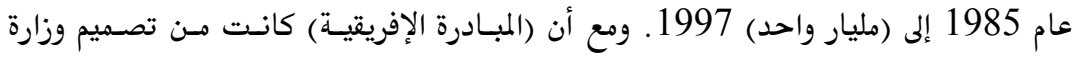

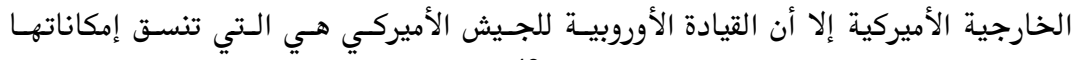
العسكرية لاسيما اللجوء إلى الوحدات الخاصة. (22). المث أعادت إدارة الرئيس بوش في عام 2002، تنظيم المديم (المبادرة الإفريقية) لتصبح (برنسامج

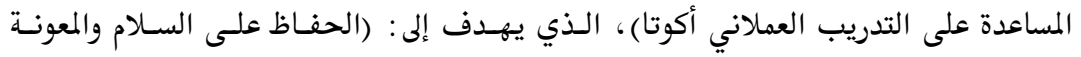

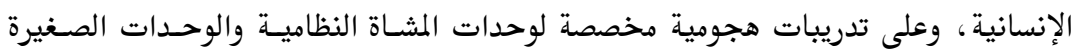

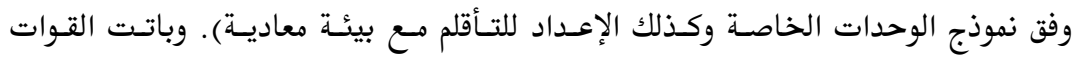

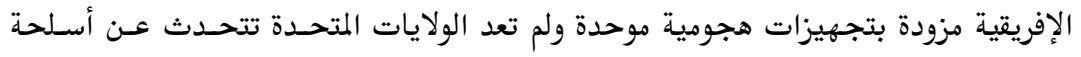

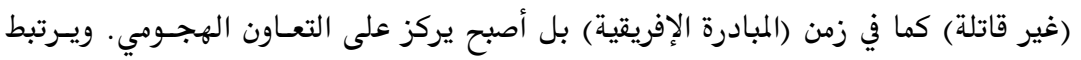

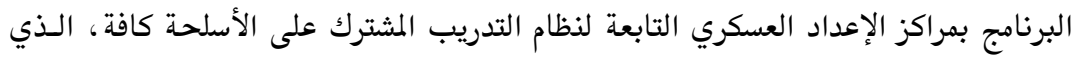

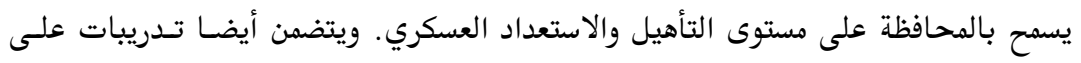

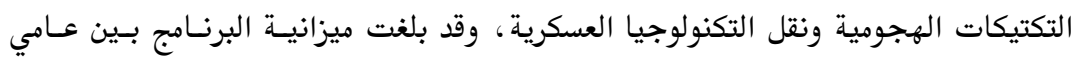
(2001-2003) ما يقارب الـ (100 مليون دولار)(43).

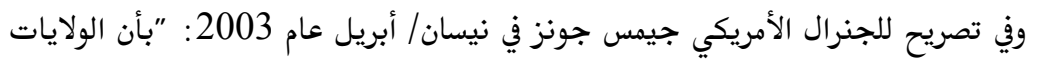

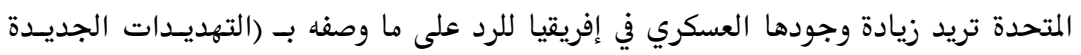

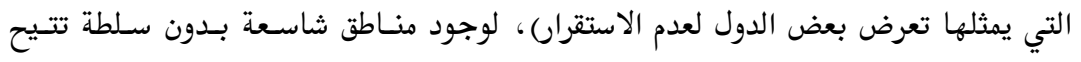


المجال لنشاط تجارة المخدرات وتدريب الإرهابيين، معلنا أن وزارة الـدفاع الأمريكيـة تنـوي

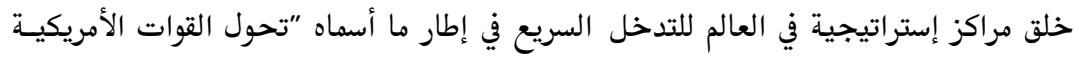
لجعلها أكثر قدرة على التحرك" (44).

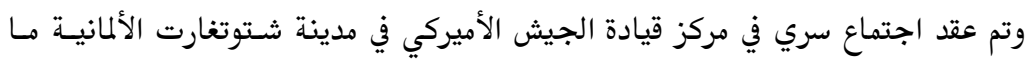

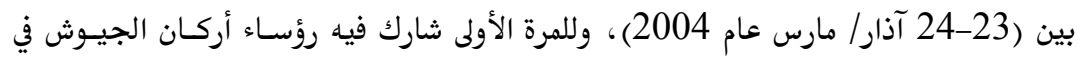

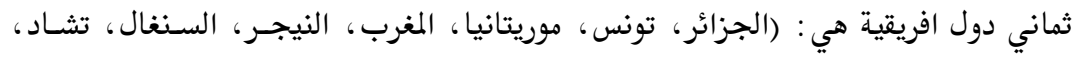

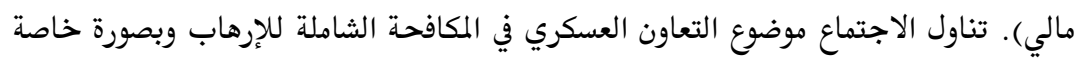
في منطقة الساحل الفاصلة بين المغـرب وإفريقيـا السـوداء، بـين المنـاطق النفطيـة في الشـمال وخليج غينيا(45). وفي إطار تعزيز علاقات التعاون بين الولايات المتحدة والمغرب بشان محاربـة الإرهـاب،

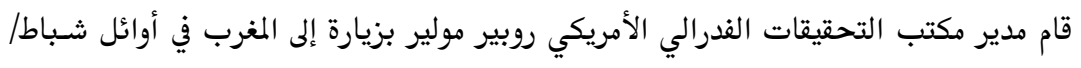

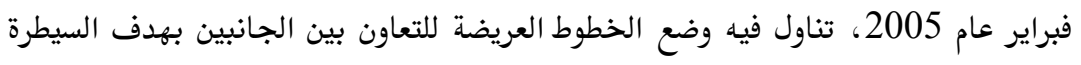

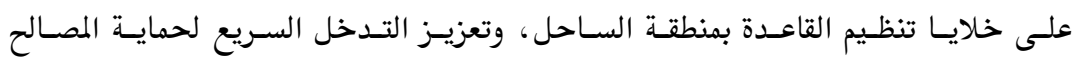

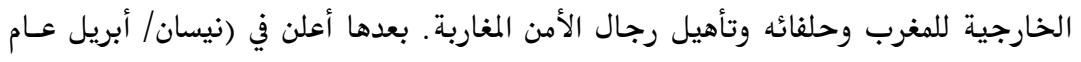

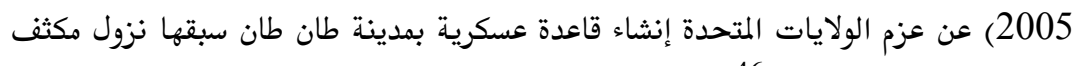
للجنود الأمريكيون بالمدينة (46).

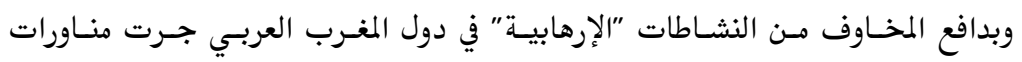
أمريكية أطلسية مشتركة مع قوات تسع دول أفريقية : (تونس والمغرب والجزائر وموريتانيـا

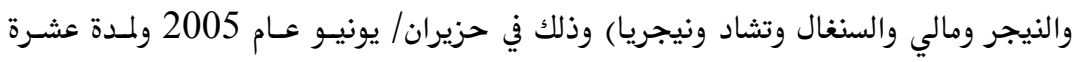

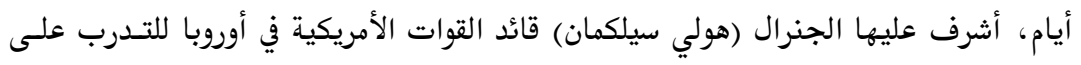

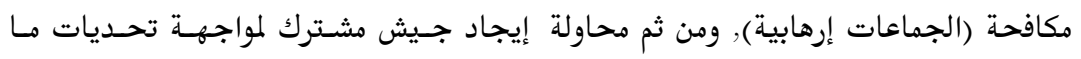

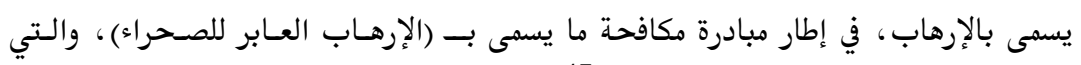
خصصت له واشنطن (100 مليون دولار) (47).

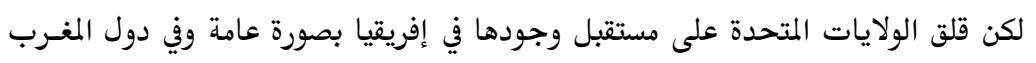

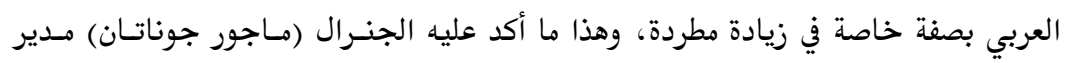


المخابرات والسياسة وعمليات التقييم بقيادة القوات الأمريكية المرابطة بأوروبـا خـلال مائـدة

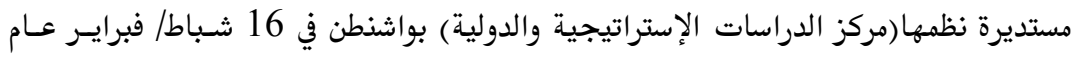
2006: "أن خطر الإرهاب أحدث تغييرا هاما في إستراتيجية الولايات المتحدة على اعتبـار

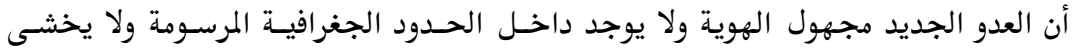
الموت, ومن ثم يتعين التحرك بشكل وقائي لمواجهته"(48.

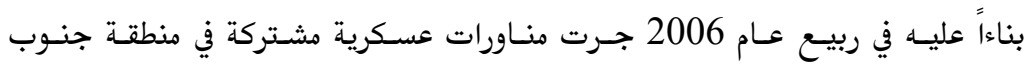
الصحراء الكبرى وكانت بمثابة تدريب على تعقـب عناصـر مرتبطـة بتنظيم القاعـدة تقـول

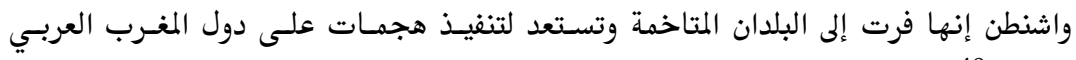
وأوروبا (49).

أعلن وزير الدفاع الأمريكي "روبرت جيتس" في شباط/ فبراير عام 2007: "أن الـرئيس

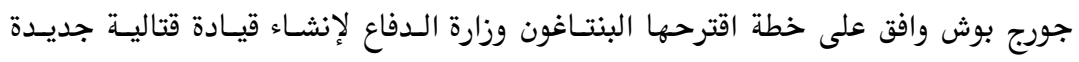

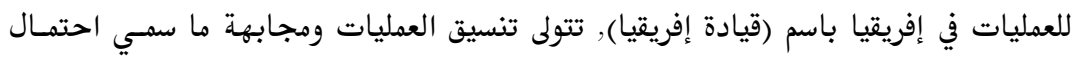

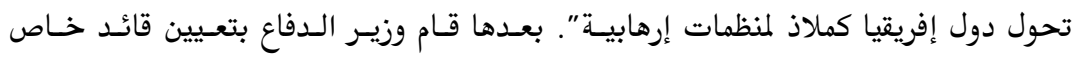

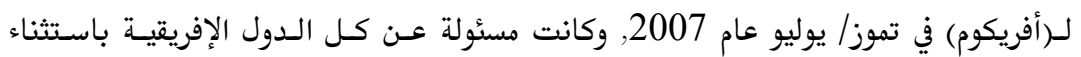
مصر)

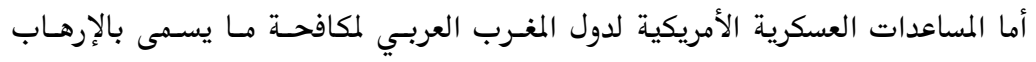

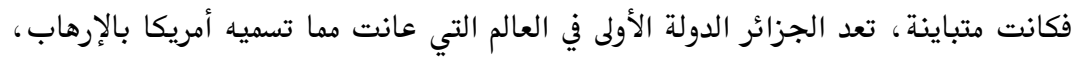

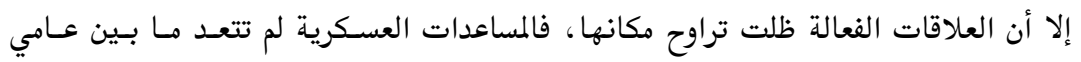

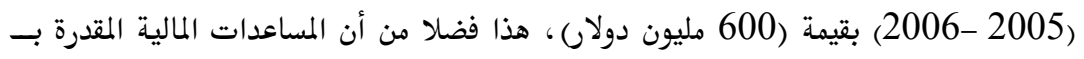

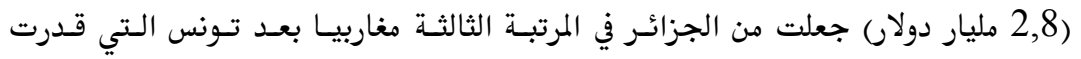

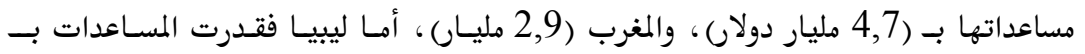
(1,15) مليار) في حين كشفت وثيقة حديثة قدمتها الخارجيـة الأمريكيـة حسول المسـاعدات الخارجيـة

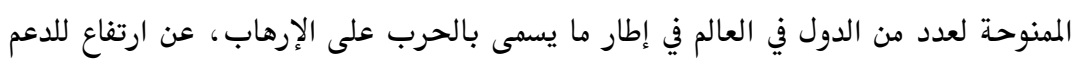

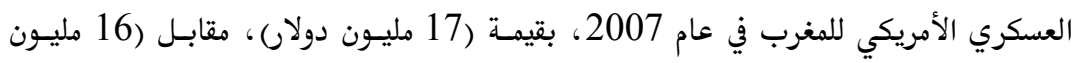




\section{3) دراسات إقليمية 8 (23)}

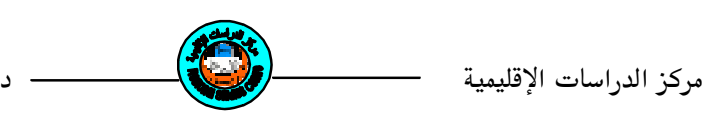

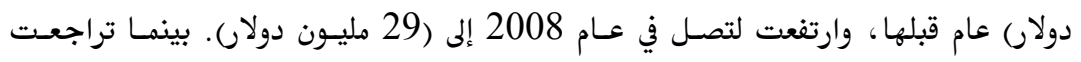

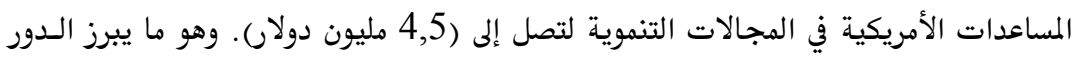

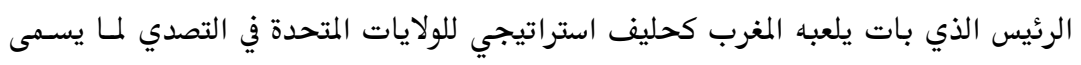

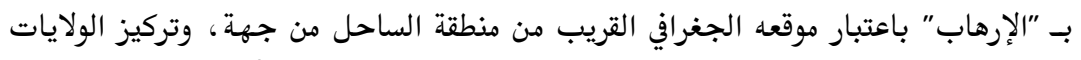
المتحدة على ما هو عسكري على حساب ما هو تنموي من جهة ثانية (52. ثالثاً: المحور الاقتصادي أن اهتمام الولايات المتحدة بأفريقيا هـو الرغبـة في تـأمين المـوارد النفطيسة لان الولايـات

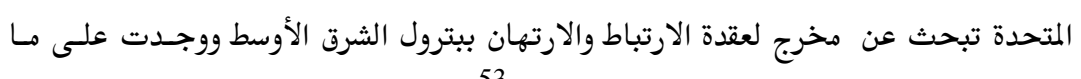
يبدو مبتغاها في البترول الإفريقي ذو الكلفة الأقل (53).

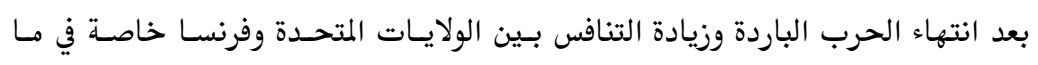

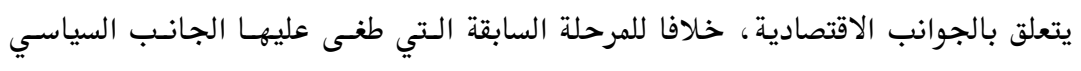

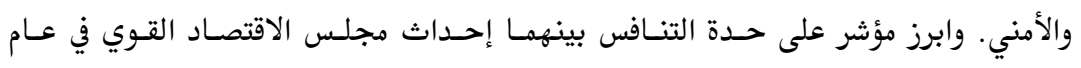

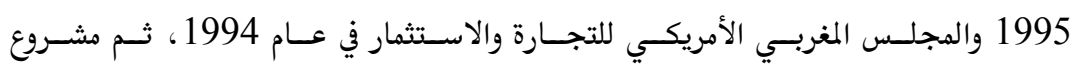

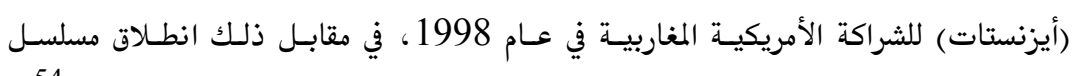

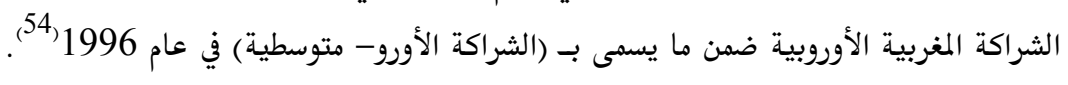

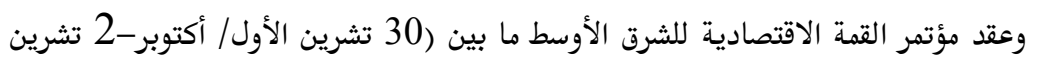

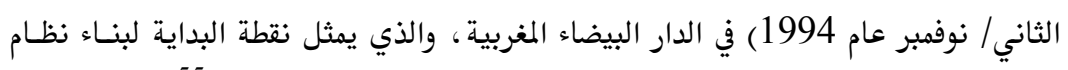

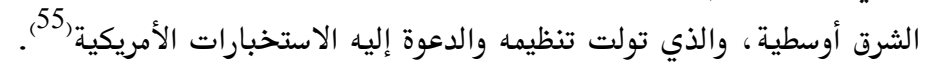

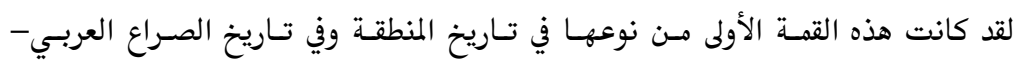

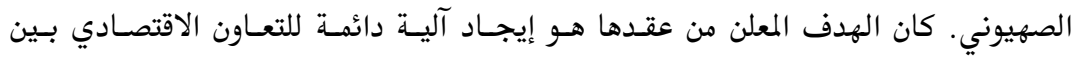
إسرائيل والدول العربية، وإلغاء المقاطعة العربية. أما الهدف الغير المعلن فهو إعطاء إسرائيل

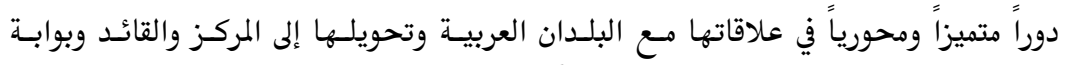
الاستيراد والتصدير من وإلى البلدان العربية(56). 


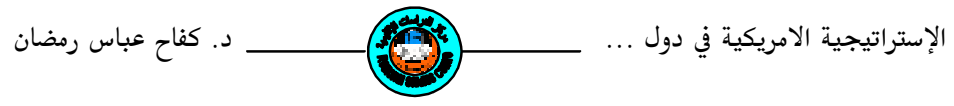

إذا سيطرت الولايات المتحدة على مخزون الـنفط الإفريقي بجانـب السيطرة على نفـط العراق فسيعني ذلك تحكمها في الاقتصاد العالمي واقتصاديات الدول المنافسة، خداصة الصدئ الصين. حيث صرح مساعد وزير الخارجية للشئون الإفريقية (والتر كانستينر) في شباط/ فبرايسر عـام إنسام

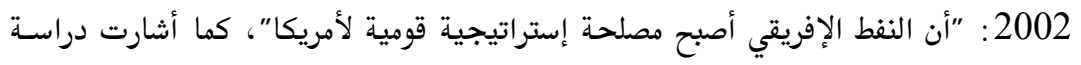

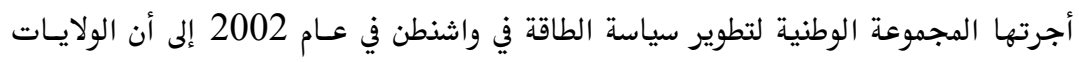

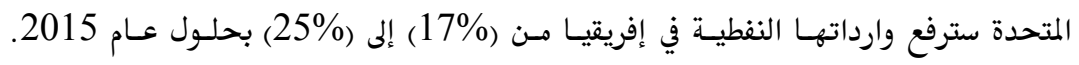

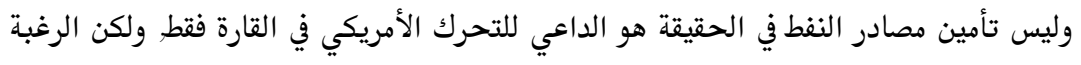
في تحجيم الـدور الصـيني المتنـامي في القـارة شـكل إحـدى زوايــا الرؤيسة الأمريكيـة حيـال إستراتيجيتها هناك(57).

عليها بدأت المفاوضات المغربية الأمريكية بهدف إقامة منطقة للتبـادل الحسر بدايسة عـام

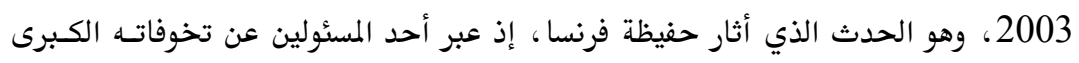

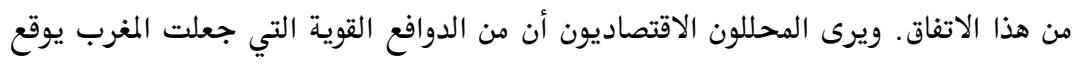

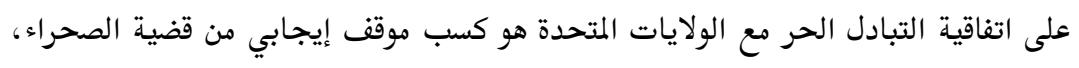

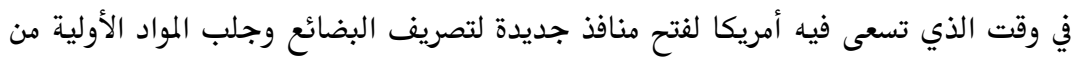

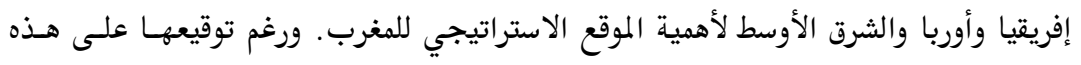

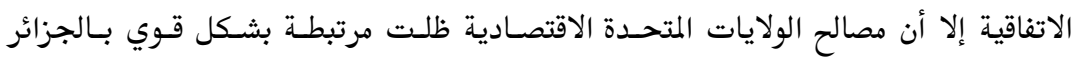

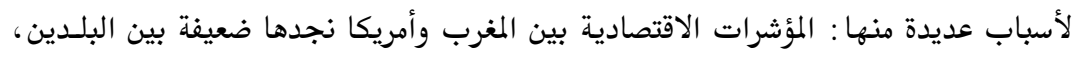

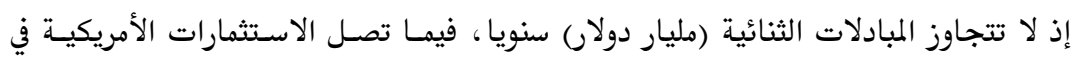

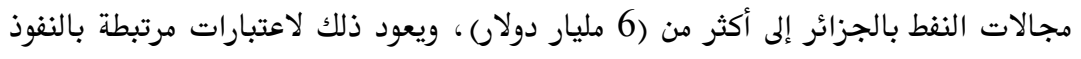

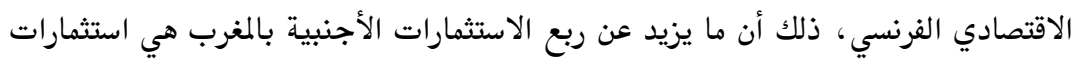

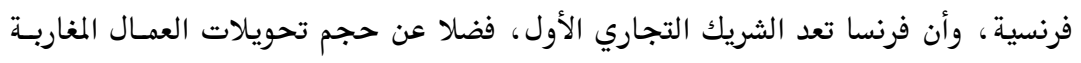

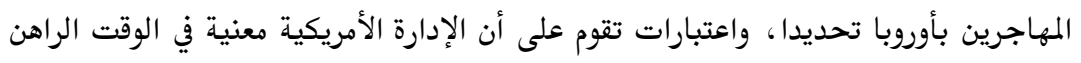

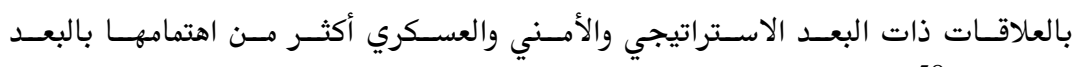
الاقتصادي (58) 


$$
\text { دراسات إقليمية } 8 \text { (23) }
$$

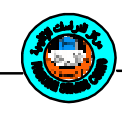

ففي 6 كانون الأول/ ديسمبر عام 2005 أصدر مجلس العلاقات الخارجية تقريسرا حـذر

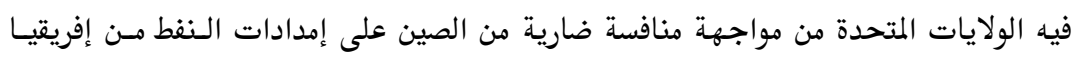

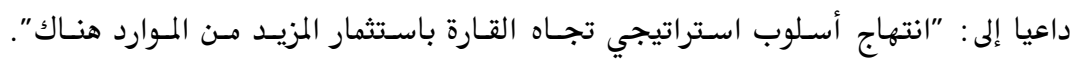

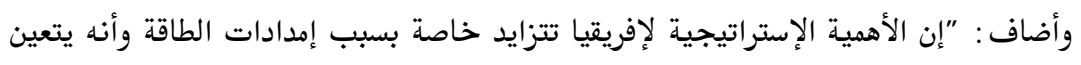

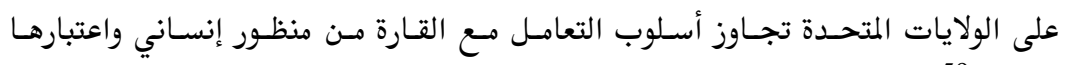
شريكا"(59).

وفي عام 2010 قام وفد من رجال الأعمال يـمثلون (24 شركة أمريكية كسبيرة) ، بجولـة

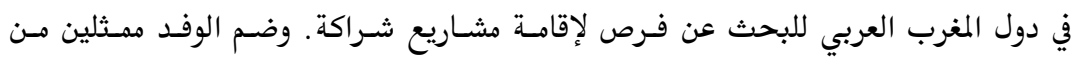

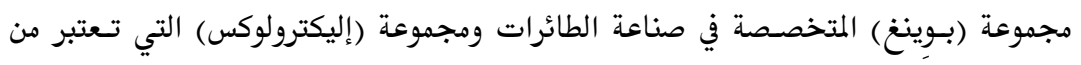

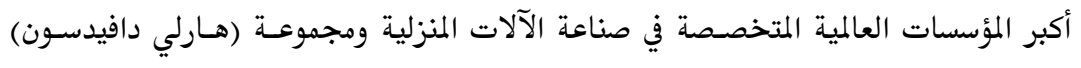

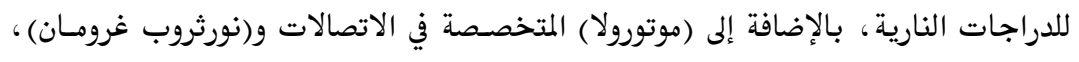

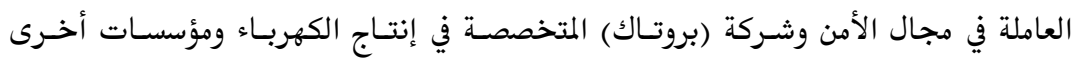

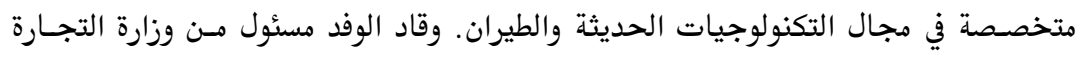

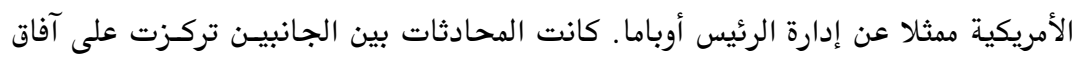

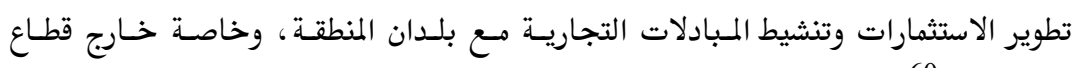
المحروقات (60). لقد أظهرت الإحصاءات أن حجـم المبادلات التجارية بين الولايات المتحدة ودول المغرب

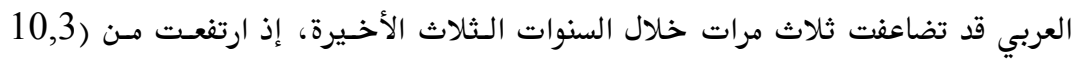

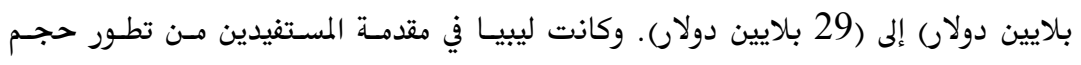

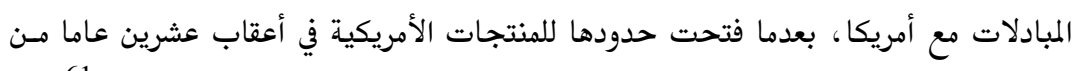

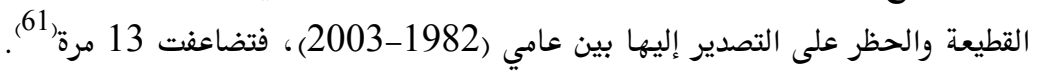


د. كفاح عباس رمضان الإستراتيجية الامريكية في دول ...

بعسد الاسـتقلال دول المغـرب العربـي انتشـرت الكليـات المتخصصـة في إطـار الجامعـة الوطنية، التي تكون عادة في العاصمة، ثم انتشرت الكليات في المحافظات الداخلية، اعتبارا

من الثمانينات حتى غدت لكل محافظة جامعتها، مثلما هو الحال اليوم في الجزائر(62). ففي المغرب توجد سـبع جامعـات عموميسة رئيسـية هـي جامعسة محمسد الأول في وجـدة وجامعة عبد الملك السعدي في طنجة، وجامعة القاضسي عيـاض في مـراكش، وجامعـة محمسد الخامس في الرباط، وجامعة الحسن الأول في سطات، وجامعة الحسن الثاني في المحمديسة،

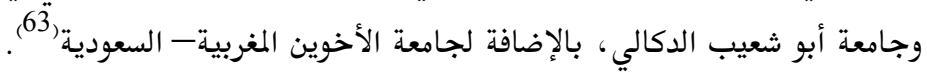
أما في تونس فتوجد ثمسان جامعسات، خمسس منهـا في العاصسمة، والسادسـة في سوسـة، والسـابعة في المنسـتير، والثامنــة في صـفاقس، وتضـم الجامعـات العموميـة (178 مؤسسـة

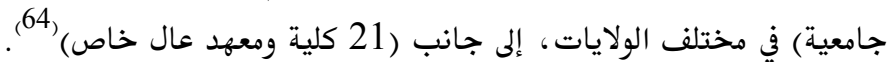
وفي الجزائر ظهرت كليات وجامعات في معظم المدن، لعل أبرزها جامعسة العلـوم هـواري بومدين في العاصمة، وجامعتى منتوري والأمير عبد القادر في قسنطينة، وجامعسة ألسـانية في وهران، وجامعة فرحات عباس في سطيف، وجامعة ابـن خلـدون في تيـارت، وجامعسة ابـن باديس في مستغانم، وجامعة مولود معمري في تيزي وزو. ولوحظ أن الجامعات المتخصصة في الآداب والعلوم الإنسانية تراجعت بشكل لافـت في السـنوات الأخـيرة، فيمـا طغـت المعاهـد التكنولوجية ومدارس الهندسة والمعلوماتية وكليات العلوم، وخاصة في القطاع الخاص، حيث يميل الطلاب إلى تلقى تعليم قصير المدى في الفروع التى تستجيب لطلبات المصـانع والمخـابر وشركات الخدمات والتأمين والمصارف (65). تجمع المؤشرات على أن الصراع على النفوذ في دول المغرب العربى بين فرنسا من جهة، والولايات المتحدة وبريطانيا من جهة أخرى، وصل إلى مرحلة التنافس الثقافي ويبدو أن اللغة الفرنسية تتجه شيئا فشيئًا إلى الانحسار أمام اللغـة الانكليزيسة في أوسـاط النخـب في تـونس إس

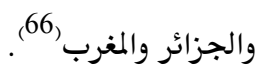
لقد احتلت فرنسا الجزائر لمدة (131 عام) وتونس لمدة (74 عـام) وموريتانيـا لمـدة (60 ولمام عام) والمغرب لمدة (44 عام)، وجعلوا من اللغة الفرنسية الجسر الثقافي الوحيد لشعوب هـذه 


\section{دراسات إقليمية 8 (23)}

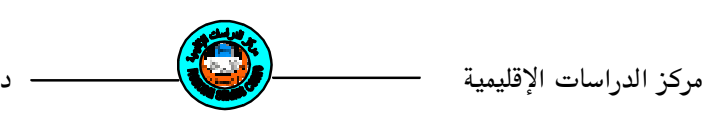

الدول نحو العالم، عدا شمال المغرب الذي كانت تحتله اسبانيا، وليبيا التي احتلتها إيطاليا

$$
\text { ثم بريطانيا (67). }
$$

لكن بعد مرحلة الاستقلال، انطلق مسار الانفتـاح على لغـات جديسدة منهـا الانكليزيـة والإسبانية والإيطالية وحتى الروسية ، فضلا عن التعزيز المستمر لمركز اللغة العربية في التعليم والحياة العامة مما قلص بدوره من نغوذ اللغة الفرنسية.

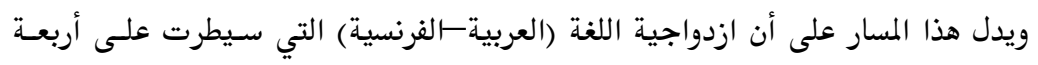

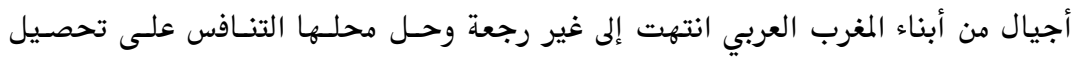
اللغات العالمية، والذي يرجح أن يمنح مكانة متفوقة للإنكليزية في المستقبل (68).

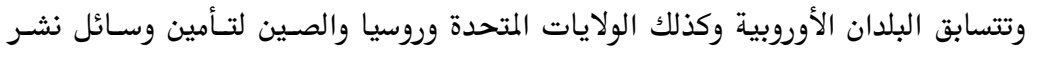

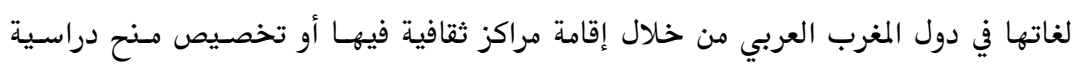

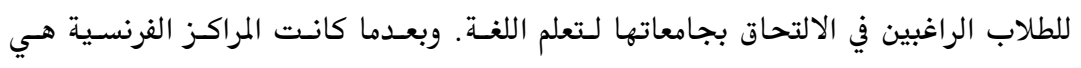

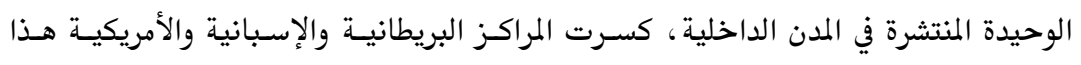

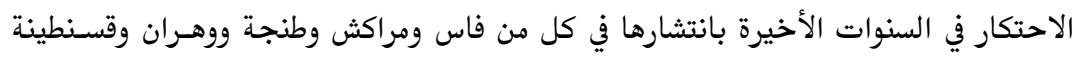
وسوسة وصفاقس إضافة للعواصم (69).

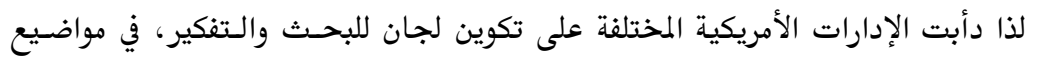

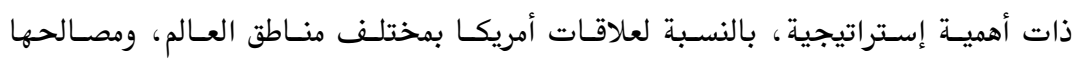

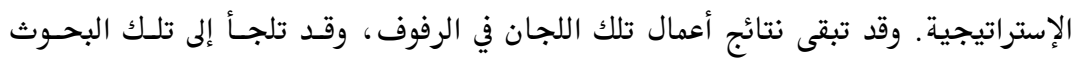

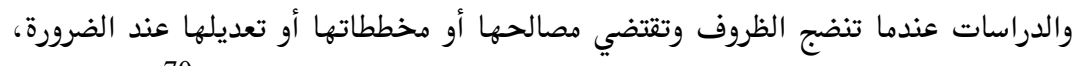

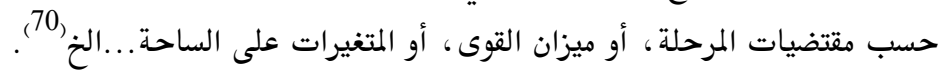

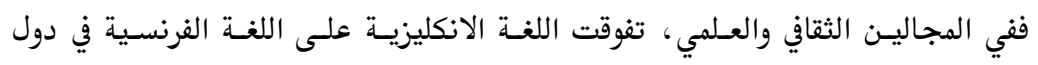

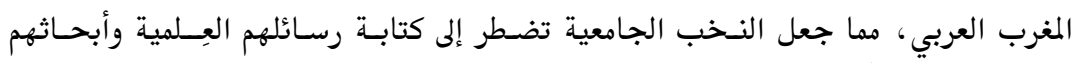
باللغة الانكليزية(11). وشكلت الجولة المغاربية التي ترأسها البروفسور إلياس زرهوني، موفد الرئيس الأمريكي

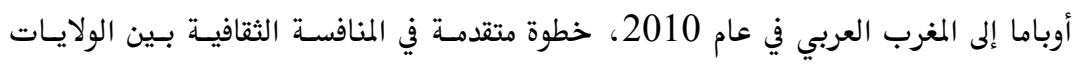

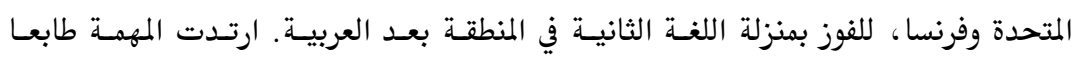


علميا- لـغويا- تـقنيا في إطار مساعي الولايات المتحدة لتعزيز وجودها الثقافي في دول المغرب

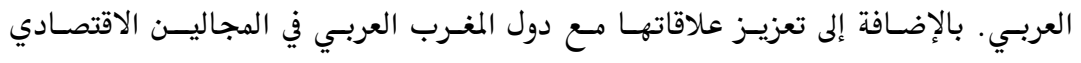

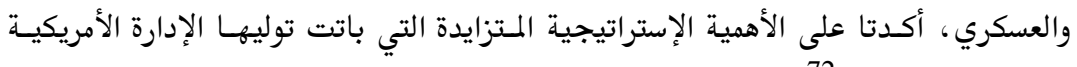

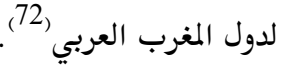

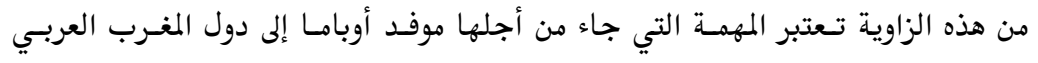

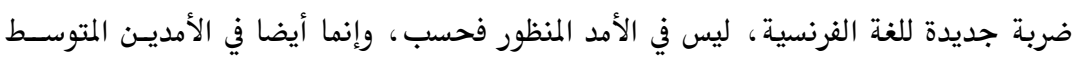

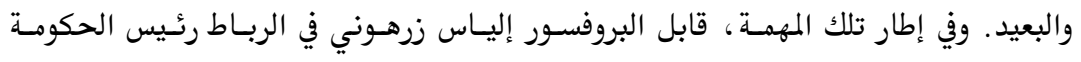

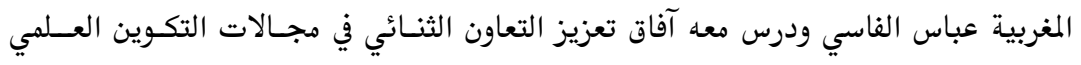

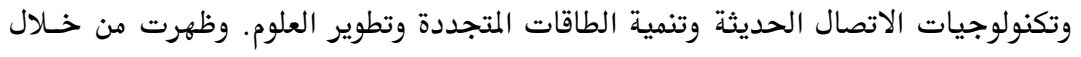

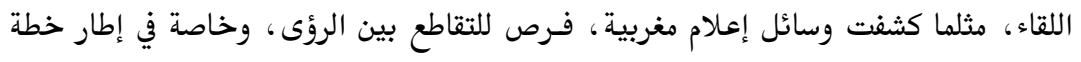

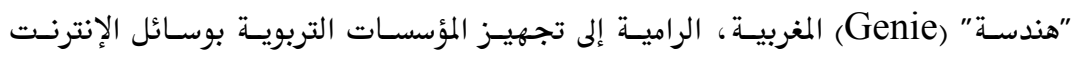

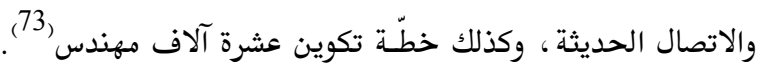

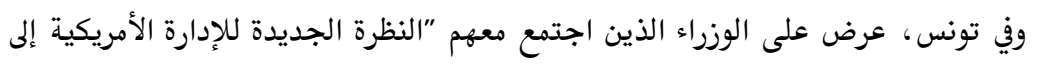

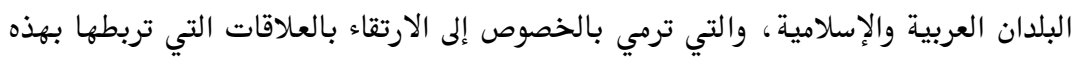

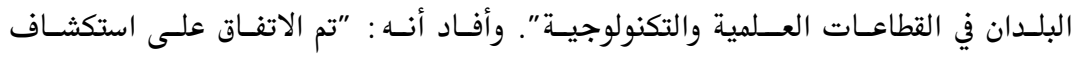

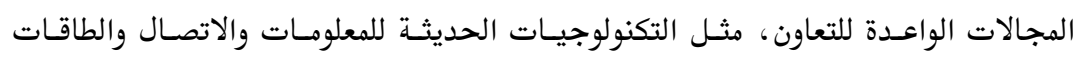
المتجددة والتصـرف في المساء والصـحة والسـلامة الغذائيسة واستثمارها في إطـار الشـراكة بـين البلدين" (74). - (المتجدة والتص

ومن النقاط التي جرى الاتفاق عليها، تدعيم التكوين في اللغة الانكليزية وتعزيز الصـلات

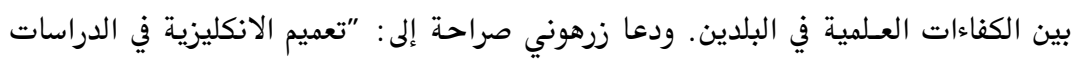

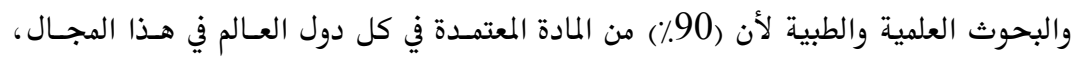

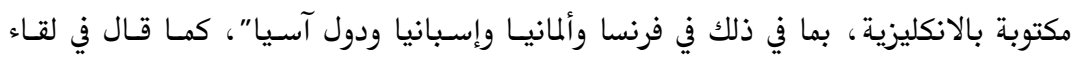

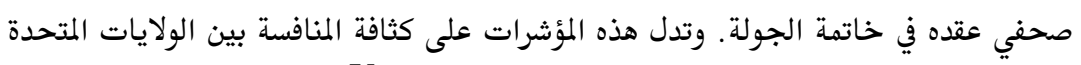
وفرنسا على التقارب مع دول المنطقة وتعزيز التعاون الثنائي (75). 
ترى الولايات المتحدة في المغرب العربي منطقـة حيويـة لمصـالحها، وتتجلسى أهميتـه في

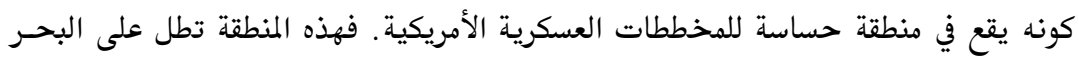

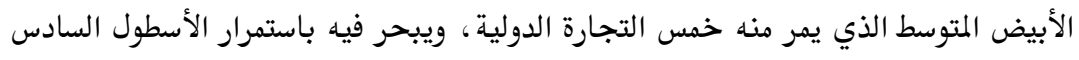

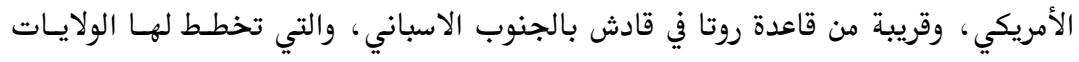

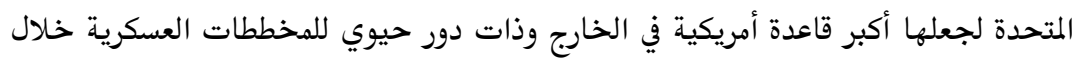

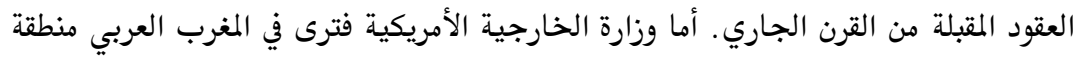

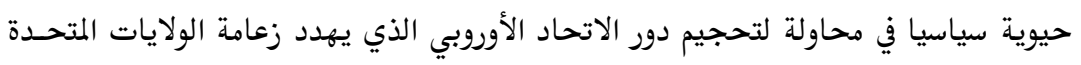
على العالم مستقبلا. إن الاهتمام الأمريكي بالمنطقة ينطوي على عدة ملفات أمنية واقتصادية ، والملف الأمسني

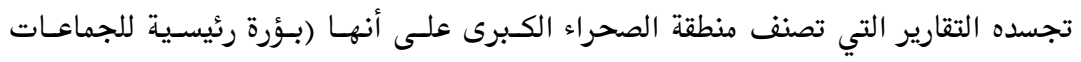

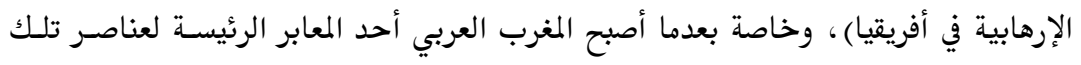

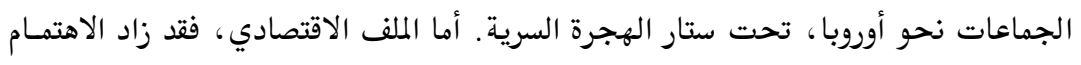

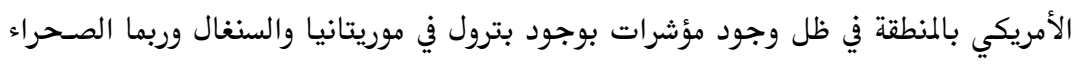

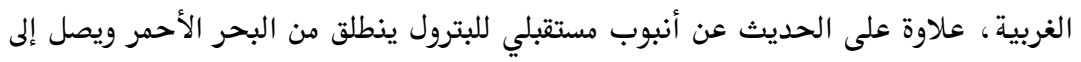

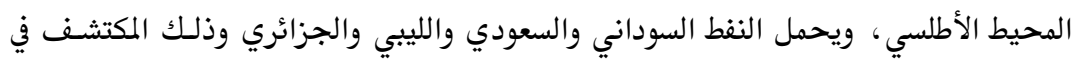

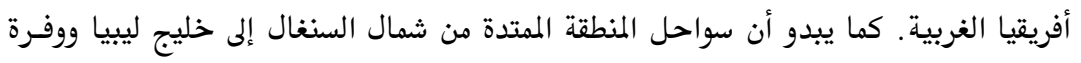

$$
\text { الطاقة والإنتاج الزراعى والمعدنى مغرية للجانب الأمريكى. }
$$

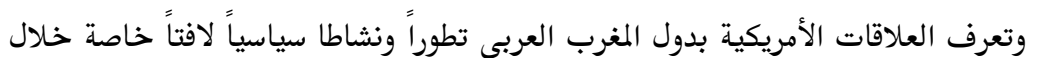

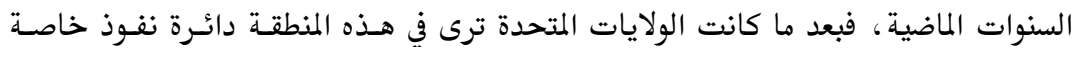

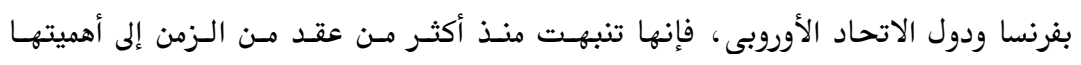

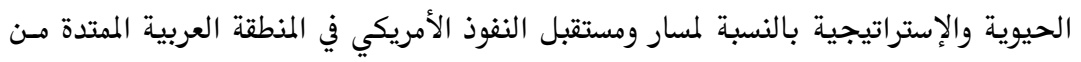


د. كفاح عباس رمضان الإستراتيجية الامريكية في دول .

الخليج إلى المحيط. فالولايات المتحدة كما هو واضح، تريسد أن تستفيد مسن المزايـا المتعددة التى توفرها كل دولة من دول المغرب العربى.

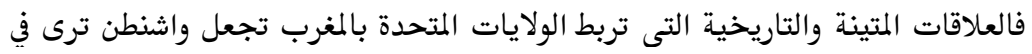
هذه الدولة واحة للاستقرار السياسى والاجتماعى، وهو مؤشر بالغ الأهمية بالنسبة للولايات

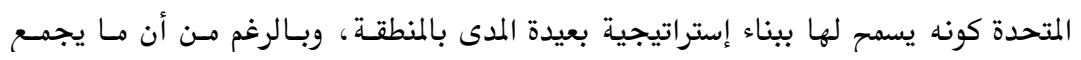

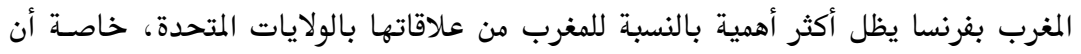
المغرب يمثل الشريك الاستراتيجى الأول لفرنسا بالمنطقة حتى قبل تونس بصرف النظر عـن الطابع الديناميكى للعلاقات التونسية الفرنسية ، فـالمغرب يحظى بوضسع تفضسيلى ومتميـز بالنسبة للفضاء الاقتصادي لدول الاتحاد الأوروبى.

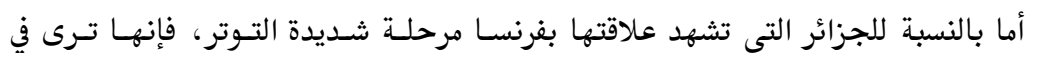

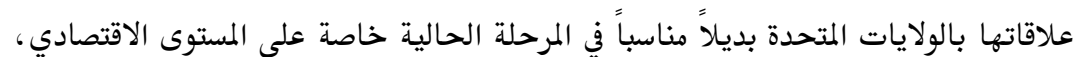

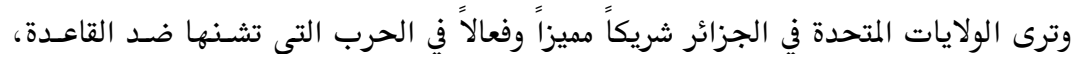

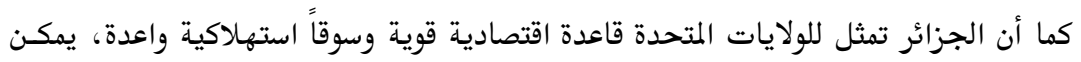

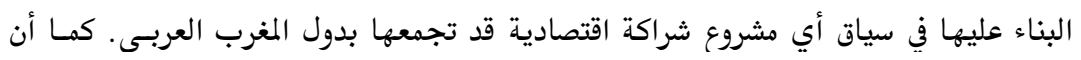
الجزائر تمثل بالنسبة للولايات المتحدة بوابة إستراتيجية لعلاقاتها المستقبلية بدول السـاحل

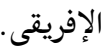

أما العلاقات التونسية الأمريكية فأنها شبيهة إلى حد بعيد بالعلاقات المغربية الأمريكيـة

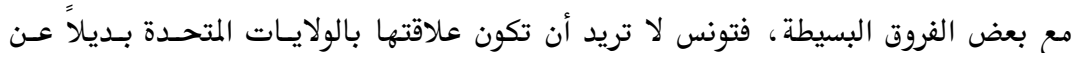

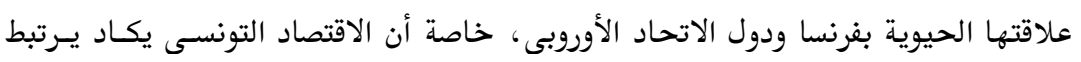

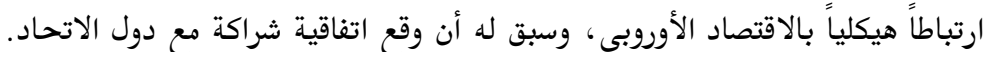

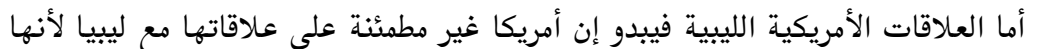

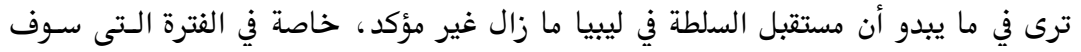

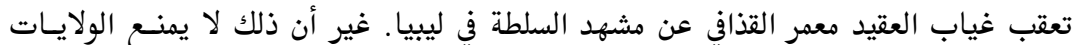

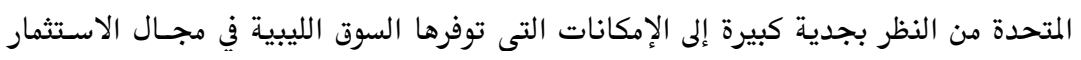

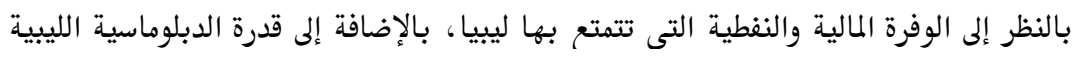
على القيام بمهمات حاسمة خصوصا في تسوية النزاعات في إفريقيا. 


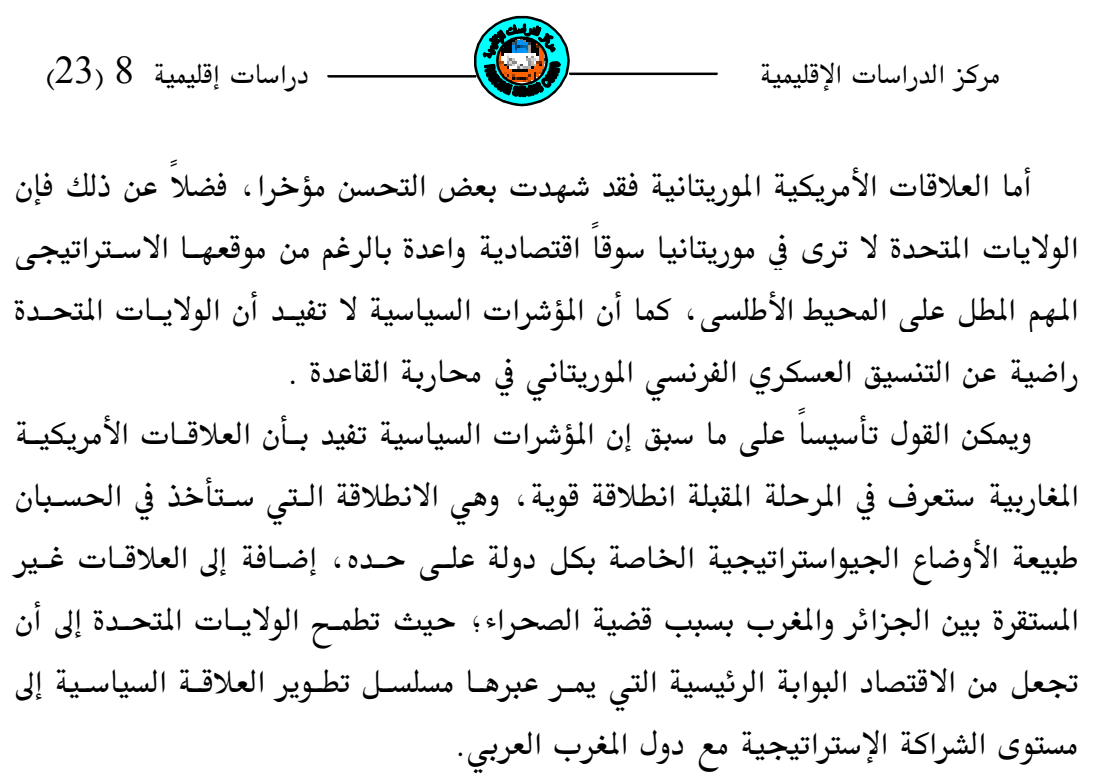

\title{
U.S. Strategy In Arab Maghreb States
}

\section{Dr. Kifal Albas Ramadan Al-Hamadani Lectures, Historical $\&$ Cultural Dept. Regional Studies Center}

\begin{abstract}
U.S. Strategy towards Arab Maghreb States can't be separated from the relations between these states and the international powers aiming to reinforce their influence in this region. The difference is clear in the domain of the ideological type in U.S. dealing with the existed political systems in Arab Maghreb States and enlarging economic interests after the Cold War, Economic competition appeared between U.S. and E.U. but the U.S. ambition in the area is not moving by economic aims but the means is to join these policies with the axis of U.S. national security. This means that oil,
\end{abstract}




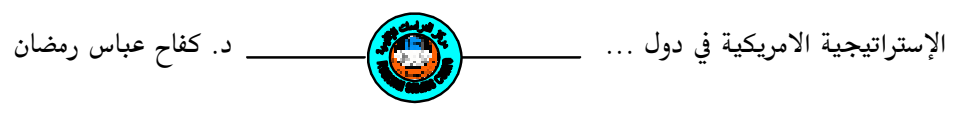

security and military expansion especially after September, 11, 2001.

$$
\begin{aligned}
& \text { الهوامش }
\end{aligned}
$$

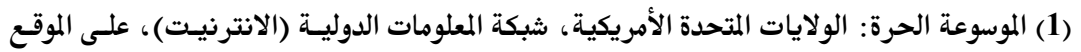

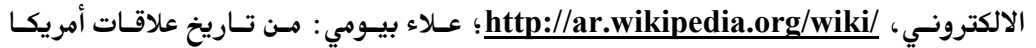

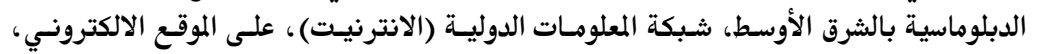

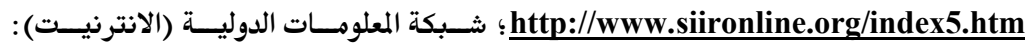

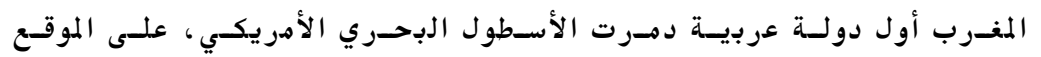

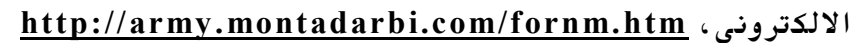

$$
\begin{aligned}
& \text { (2) محمد ناصر : تاريخ العدوان الأمريكى المخزي على الشعوب العربيـة الإسلامية في شمـال إفريقيـا، }
\end{aligned}
$$

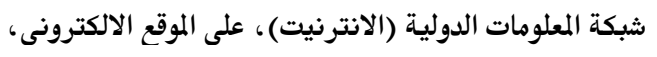

$$
\begin{aligned}
& \text { (3) (3) الموسوعة الحرة، الولايات المتحدة الأمريكية. }
\end{aligned}
$$

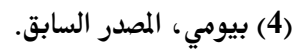

$$
\begin{aligned}
& \text { (5) ناصر، المصدر السابق؛ بيومي، المصدر السابق. }
\end{aligned}
$$

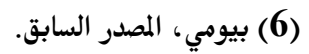

$$
\begin{aligned}
& \text { (7) شبكة المعلومات الدولية(الانترنيت)، المصدر السابق ؛ بـانيـومي، المصدر السابق؛ ناصر، المصدر }
\end{aligned}
$$

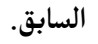

$$
\begin{aligned}
& \text { (8) بيومي، المصدر السابق؛ ناصر، المصدر السابق. }
\end{aligned}
$$

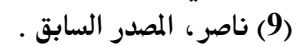

$$
\begin{aligned}
& \text { (10) بيومي، المصدر السابق؛ ناصر، المصدر السابق. }
\end{aligned}
$$




$$
\text { دراسات إقليمية } 8 \text { (23) }
$$

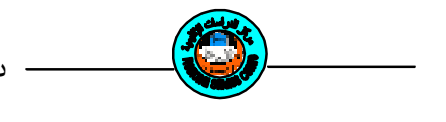

مركز الدراسات الإقليمية

$$
\begin{aligned}
& \text { (11) ناصر، المصدر السابق. } \\
& \text { (12) المصدر نفسه. } \\
& \text { (13) المصدر نفسه. }
\end{aligned}
$$

(15) (الموسوعة الحرة، الولايات المتحدة الأمريكية.

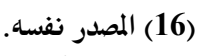

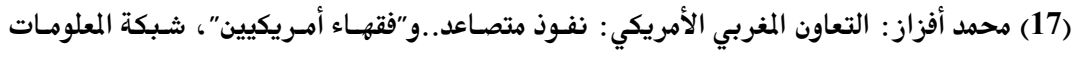
http://almoslim.net.

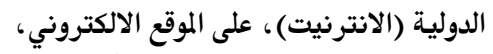

$$
\begin{aligned}
& \text { (18) الموسوعة الحرة، الولايات المتحدة الأمريكية. }
\end{aligned}
$$

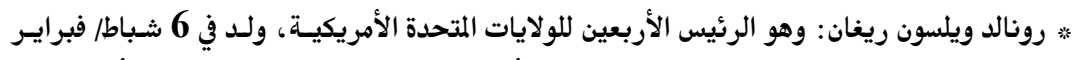

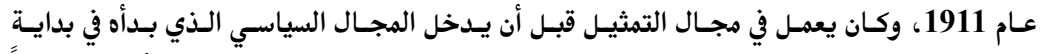

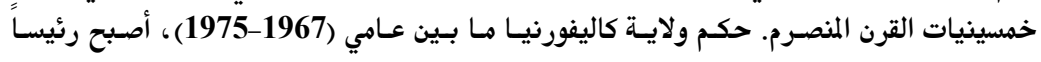

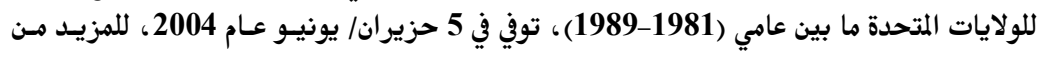

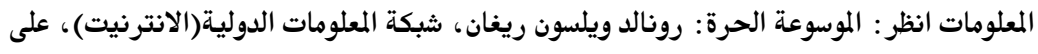

\section{http://ar.wikpedia.org/wiki/}

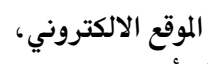

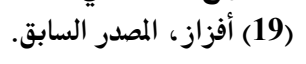

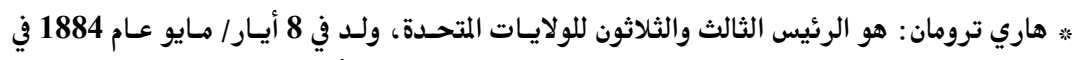

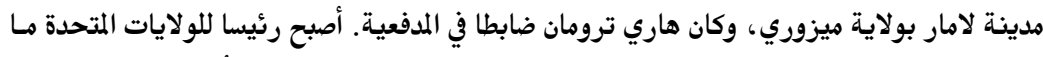

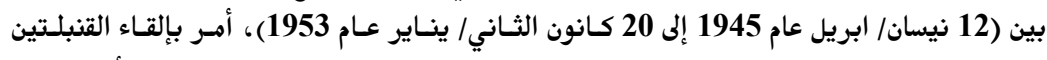

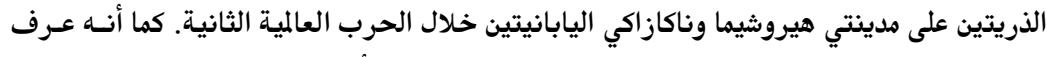

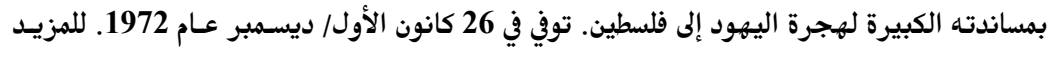

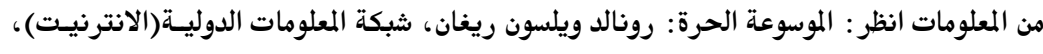

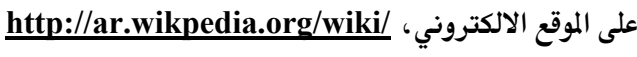

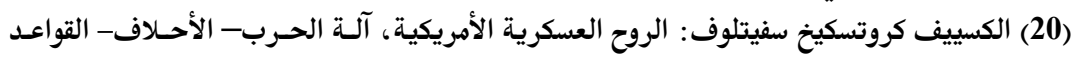

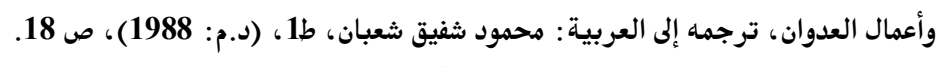

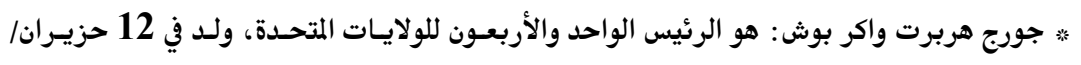

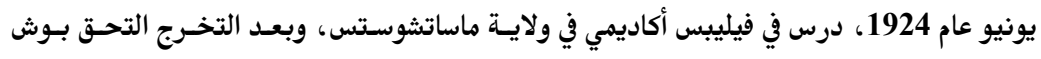

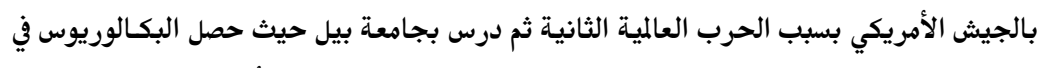

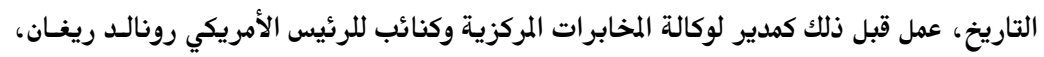

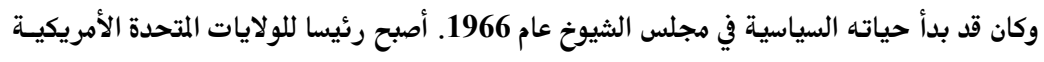

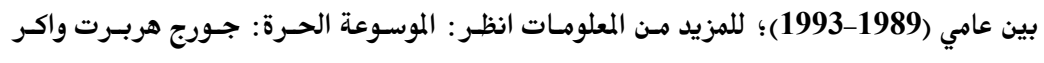

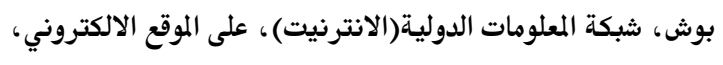




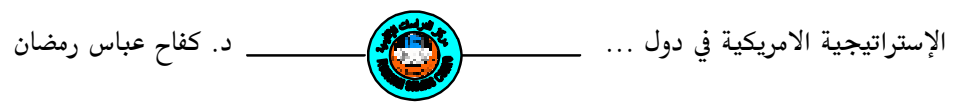

\section{http://ar.wikpedia.org/wiki/}

(21) غــــي فيصـل حســين: العلاقـات الجيوسياسـيـة الأمريكيــة الإفريقيسة، شـبكة المعلومسـات http:/Www.almusallh.ly/الدولية(الانترنيت)، على الموقع الالكتروني،

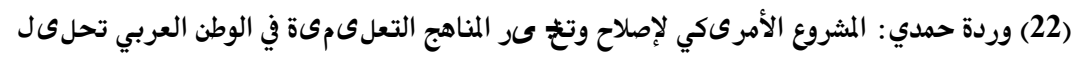

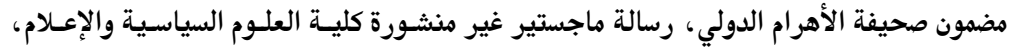

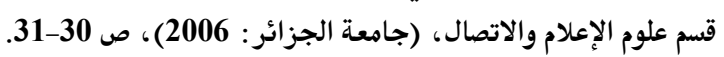

(23) شبكة المعلومات الدولية (الانترنيت) : إفريقيـا...آتـون الصـراعات وبحسر الثروات، على الموقـع

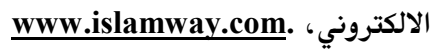

(24) حمدي، المصدر السابق، ص 62.

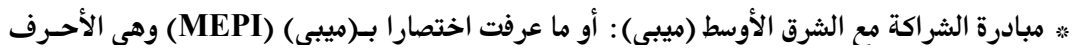

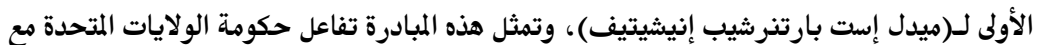

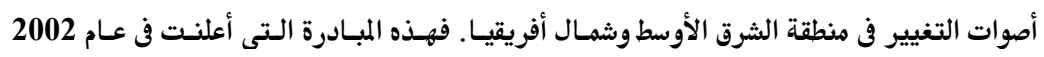

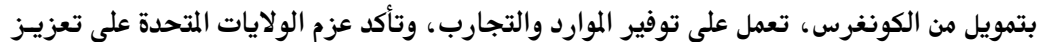

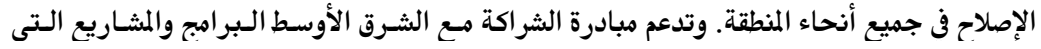

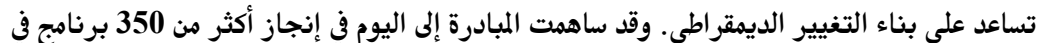

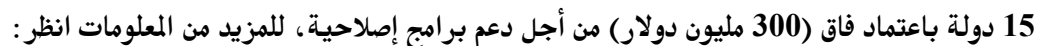

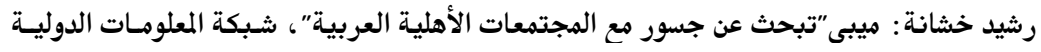

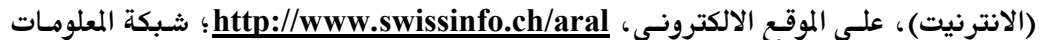

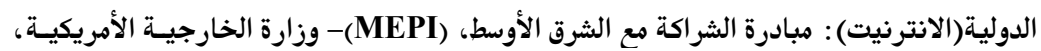

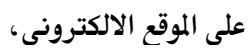

http://mepi.state.gov/

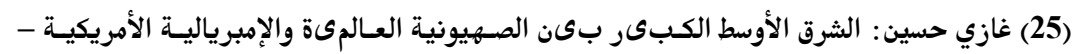

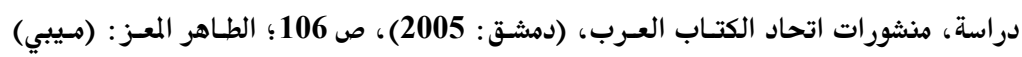

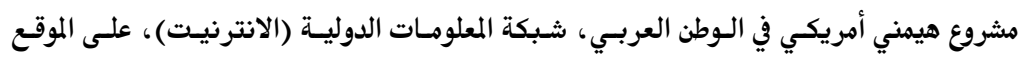

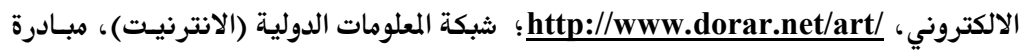

$$
\begin{aligned}
& \text { الشراكة مع الشرق الأوسط. } \\
& \text { (26) حسىن، الشرق الأوسط الكبير، ص الاوسط الشرق } 105 . \\
& \text { (27) المصدر نفسه، ص 106؛ المعز، المصدر السابق؛ شبكة المعلومسات الدوليسة (الانترنيـت)، مبـادرة }
\end{aligned}
$$

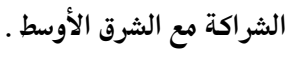




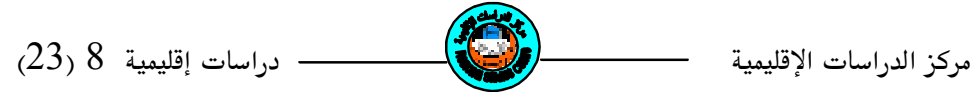

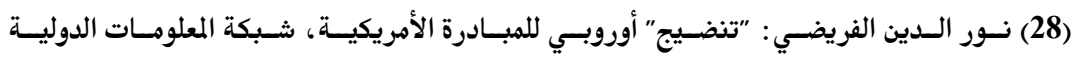

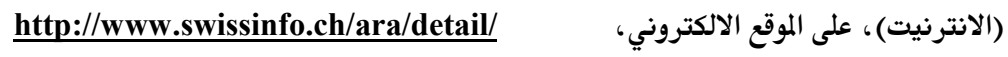

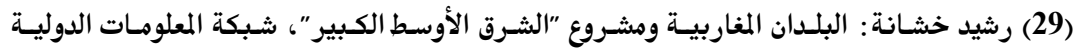

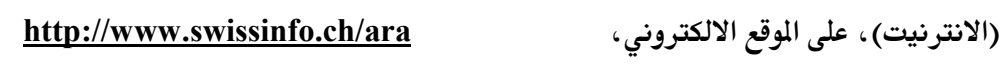

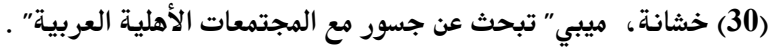

$$
\begin{aligned}
& \text { (31) (31) المصدر نفسهة }
\end{aligned}
$$

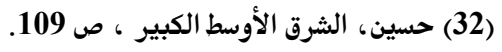

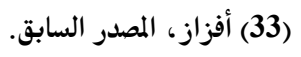

$$
\begin{aligned}
& \text { (34) المصدر نفسه. } \\
& \text { * باراك حسين أوباما : هو الرئيس الرابع والأربعـون للولايـات المتحسدة، ولد في } 4 \text { آب/ أغسطس عـام }
\end{aligned}
$$

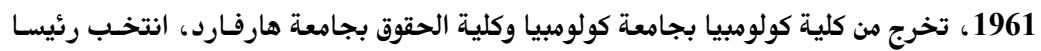

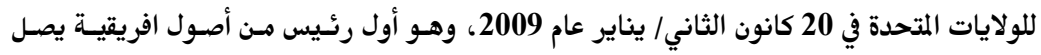

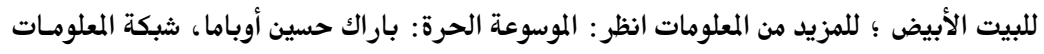

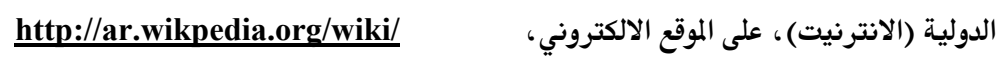

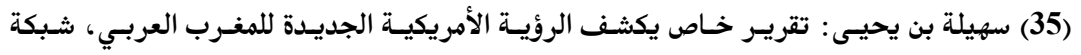

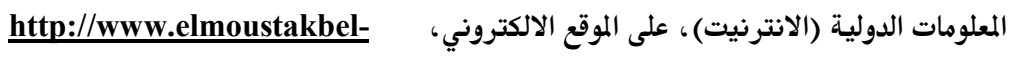

$$
\begin{aligned}
& \text { dz.com } \\
& \text { (36) الحسين الزاوي: أمريكا والمغـرب العربي، شبكة المعلومـات الدوليـة(الانترنيـت)، على الموقع }
\end{aligned}
$$

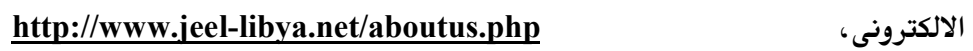

$$
\begin{aligned}
& \text { (37) خلف المنشدي: مرتكزات الإستراتيجية العسكرية الأمريكية وصناعة الحسرب، شبكة المعلومسات }
\end{aligned}
$$

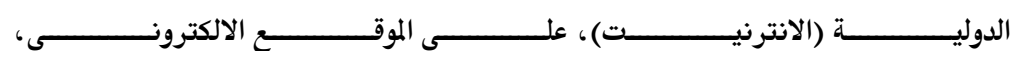

$$
\begin{aligned}
& \text { http://www.almannarah.com/mobile } \\
& \text { (38) (38) المصدر نفسه. }
\end{aligned}
$$

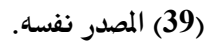

$$
\begin{aligned}
& \text { (40) سفيتلوف، المصدر السابق، ص } 3 . \\
& \text { (41) المصدر نفسه، ص } 14 \text { (40. }
\end{aligned}
$$




$$
\begin{aligned}
& \text { د. كفاح عباس رمضان } \\
& \text { (2) } \\
& \text { بعد نهاية الحرب الباردة؛ للمزيد من المعلومات انظر : الموسوعة الحرة: ويليام جيفرسون كلينتون، }
\end{aligned}
$$

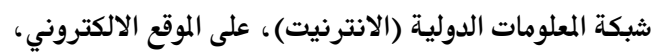

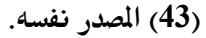

$$
\begin{aligned}
& \text { (44) شبكة المعلومات الدولية(الانترنيت)، إفريقيا...آتون الصراعات. } \\
& \text { (45) حسين، العلاقات الجيوسياسية الأمريكية الإفريقية. }
\end{aligned}
$$

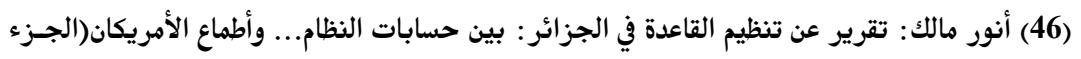

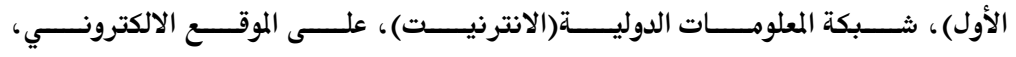

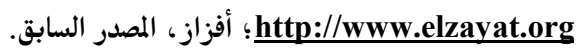

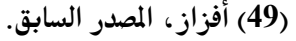

$$
\begin{aligned}
& \text { شبكة المعلومات الدولية(الانترنيت) ، على الموقع الالكتروني، }
\end{aligned}
$$

\section{http://www.almusallh.ly/strategic-studies}

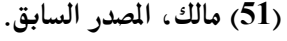

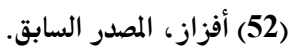

$$
\begin{aligned}
& \text { (53) شبكة المعلومات الدولية (الانترنيت)، إفريقيا...آتون الصراعات. }
\end{aligned}
$$

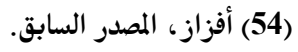

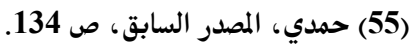

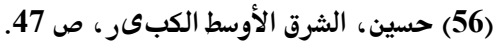

$$
\begin{aligned}
& \text { (57) شبكة المعلومات الدولية(الانترنيت)، إفريقيا...آتون الصراعات وبحر الثروات. }
\end{aligned}
$$

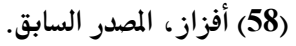

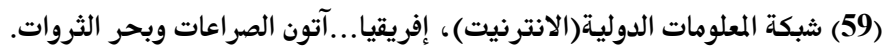

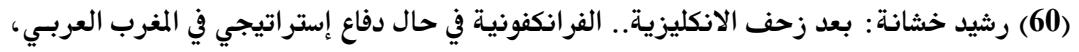

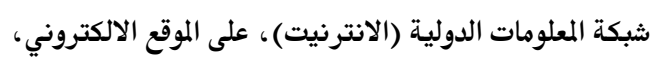

http://www.swissinfo.ch/ara

$$
\text { (61) المصدر نفسه. }
$$




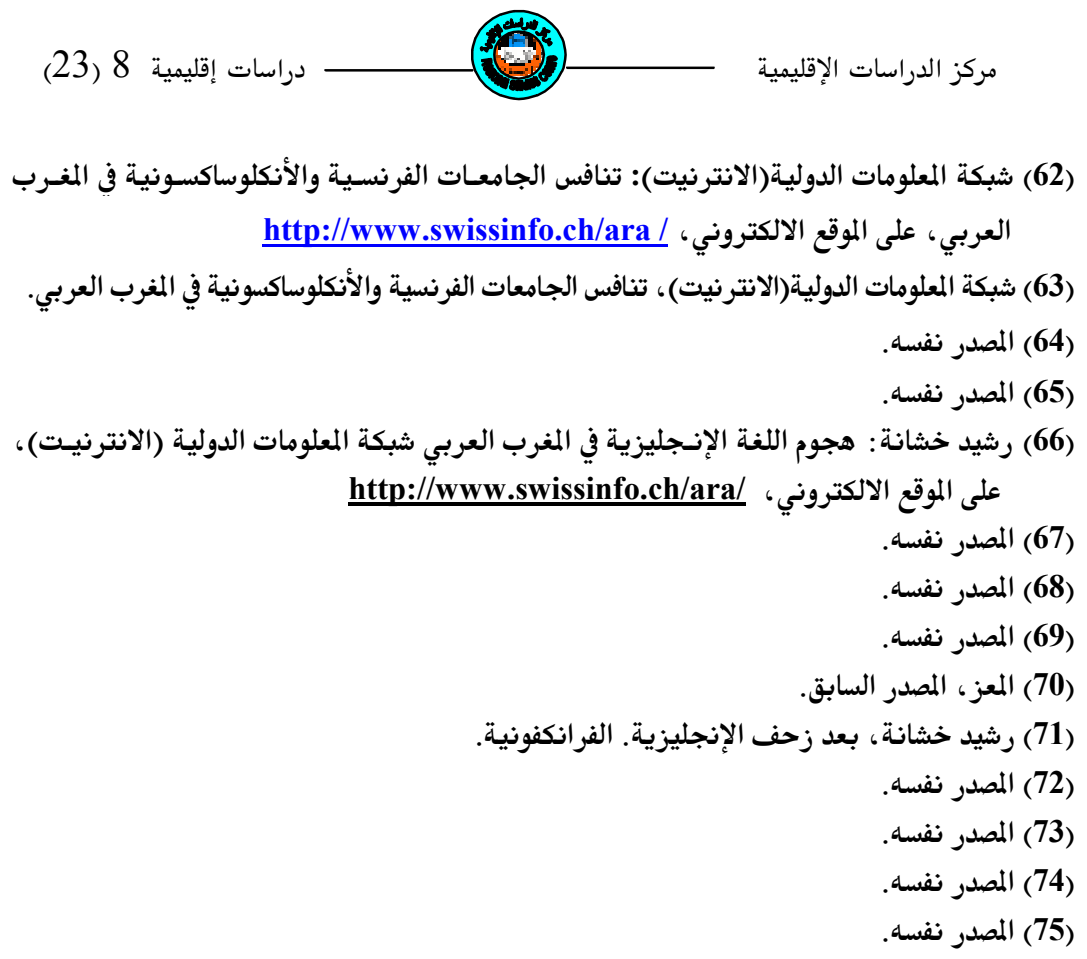

